\title{
Selective Adsorption and Photocatalytic Degradation of Dyes Using Polyoxometalate Hybrid Supported on Magnetic Activated Carbon Nanoparticles under Sunlight, Visible, and UV Irradiation
}

\author{
Mehdi Taghdiri ${ }^{1,2}$ \\ ${ }^{1}$ Department of Chemistry, Payame Noor University, Tehran 19395-3697, Iran \\ ${ }^{2}$ Research Center of Environmental Chemistry, Payame Noor University, Ardakan, Yazd, Iran \\ Correspondence should be addressed to Mehdi Taghdiri; mehditaghdiri@yahoo.com
}

Received 15 March 2017; Revised 4 June 2017; Accepted 5 June 2017; Published 24 July 2017

Academic Editor: Mark van Der Auweraer

Copyright (c) 2017 Mehdi Taghdiri. This is an open access article distributed under the Creative Commons Attribution License, which permits unrestricted use, distribution, and reproduction in any medium, provided the original work is properly cited.

\begin{abstract}
In this study, magnetic activated carbon (MAC) nanoparticles were coated with an organic hybrid of silicotungstic acid that makes MAC suitable for adsorption and photocatalytic degradation of dyes. The prepared composite was characterized by Fourier transform infrared spectroscopy, powder X-ray diffraction, thermal analyses, scanning electron microscopy, vibrating sample magnetometer, and $\mathrm{N}_{2}$ adsorption-desorption isotherms. Dye adsorption and photocatalytic properties of composite were examined by studying the decolorization of model dyes methylene blue (MB), methyl orange (MO), rhodamine B (RhB), and their mixture solutions. The results show that the composite can selectively adsorb MB molecules from binary mixtures of $\mathrm{MB} / \mathrm{MO}$ or $\mathrm{MB} / \mathrm{RhB}$, and its adsorption capacity is enhanced as compared with the MAC. The composite is also, unlike MAC, a good photocatalyst in the degradation of dyes under sunlight, visible, and UV irradiation and can be separated by magnet, recovered and reused. Removal is via combination of adsorption and then photocatalytic degradation through direct oxidation by composite or indirect oxidation by ${ }^{\bullet} \mathrm{OH}$ radicals. While the sunlight is not able to degrade alone $\mathrm{MO}$ and $\mathrm{RhB}$ solution in the presence of composite, it degrades the MO and RhB mixed with MB solution.
\end{abstract}

\section{Introduction}

Synthetic dyes have been widely used in many technological processes such as paints and textiles, as an additive in plastic, paper, leather, cosmetics and rubber industries, and so on [1]. The discharge of wastewater of these industries to the environment affects both living organisms of aquatic ecosystems and human health due to toxicity and carcinogenicity [2]. Consequently, treatment of dye-contaminated wastewaters with decontamination processes is necessary before their discharge. Adsorption of dyes on inexpensive and efficient solid supports especially on activated carbon (AC) and AC composites is one of the simplest and most economical methods for removing dyes from wastewater [3-19]; however, the disposal of residues is still a problem. Advanced oxidation processes (AOPs) are widely accepted as an efficient method for dye-contaminated wastewater due to complete degradation of organics into carbon dioxide and water. Among various AOPs, heterogeneous photocatalysis has attracted significant attention because of its low-cost, environmental friendliness and sustainability [20-23]. Therefore, strong efforts have been devoted to explore some novel photocatalytic materials with high activities especially under visible and sunlight irradiation. Recently, considerable attention has been focused on heteropoly acids including their anions (polyoxometalates (POMs)) due to many advantages such as simple preparation, high reactivity, noncorrosive, nonpollutant, and excellent stability. POMs have been used as photocatalysts for the reductive destruction of dyes [24]. However, although POMs exhibit an excellent photocatalytic effect, their high solubility in water and polar solvents cause difficulties in the separation and recycling from the reaction system [25]. Hence, developing of efficient heterogeneous POM photocatalysts is quite necessary. One of the approaches for the generation of POM-based heterogeneous catalysts is immobilization of POM species on various 
supports [21, 26, 27]. Dispersion of POMs on supports with high surface area increases their catalytic activity and facilitates separation.

In this work, we have used magnetic activated carbon (MAC) nanoparticles as supporting material for an organic hybrid of silicotungstic acid (STA) to prepare a heterogeneous magnetic nanophotocatalyst. The MAC nanoparticles were coated with the hexamine-silicotungstate-methylene blue (HMT-STA-MB) hybrid. To our knowledge, immobilization of POMs on MAC to remove pollutants from water has not been reported yet. The photocatalytic performance of the MAC-HMT-STA-MB composite was evaluated via photodegradation of $\mathrm{MB}, \mathrm{MO}, \mathrm{RhB}$, and mixtures of $\mathrm{MB} / \mathrm{MO}$ and $\mathrm{MB} / \mathrm{RhB}$ solutions under sunlight, visible, or UV irradiation.

\section{Experimental}

2.1. Chemicals and Reagents. Silicotungstic acid $\left(\mathrm{H}_{4} \mathrm{SiW}_{12} \mathrm{O}_{40}\right)$ (>99\%) was purchased from Merck. The hexamethylenetetramine (HMT) or hexamine powder $\left(\mathrm{C}_{6} \mathrm{H}_{12} \mathrm{~N}_{4}, 99.5 \%\right)$ was purchased from Sina Chemical Industries Co. (Shiraz, Iran). Other reagents were purchased from commercial sources and used without further purification.

2.2. Apparatus. Weighing of materials was performed using an analytical balance model Sartorius MCBA 100 with a precision of $\pm 0.0001 \mathrm{~g}$. A Labinco magnetic stirrer model L-81 was used for stirring of solutions. For $\mathrm{pH}$ measurements, a Metrohm type $691 \mathrm{pH}$ meter was used. A GBC UV-Vis spectrophotometer model Cintra 6 or Jenway 6010 spectrophotometer was used for spectrophotometric measurements. C, $\mathrm{H}$, and $\mathrm{N}$ elemental analyses were carried out on a PerkinElmer $2400 \mathrm{CHN}$ elemental analyzer. The IR spectra were obtained with $\mathrm{KBr}$ pellets using a Shimadzu 8400 s FTIR spectrometer. Scanning electron microscopy (SEM) was performed using a scanning electron microscope SEM PHENOM. X-ray diffraction patterns were carried out on a Bruker D8 advance X-ray diffractometer using $\mathrm{Cu}$ target at room temperature. The thermogravimetric analysis (TGA) and differential scanning calorimetry (DSC) of composite was performed on a Rheometric Scientific STA 1500 thermal analyzer under the atmosphere of air. A vibrating sample magnetometer (VSM, made in Kashan University) was used to characterize the magnetic properties of the composite at room temperature. The BET surface area, pore volume, and size of the composite were measured from $\mathrm{N}_{2}$ adsorptiondesorption isotherms at $77 \mathrm{~K}$ by using a surface area and pore size analyzer (Belsorp-mini II, Bel, Japan).

2.3. Preparation of MAC-HMT-STA-MB Composite. The MAC-HMT-STA-MB composite was prepared in three steps. In the first step, the HMT-STA hybrid was synthesized: $10 \mathrm{~mL}$ hexamine aqueous solution $(1.0 \% \mathrm{w} / \mathrm{w})$ was added to $10 \mathrm{~mL}$ silicotungstic acid aqueous solution $(5 \% w / w)$. A milky suspension solution resulted immediately. The reaction was continued by stirring. Then, a white precipitate was produced. The suspension was filtrated, and the collected solid was washed with distilled water and then dried at $100^{\circ} \mathrm{C}$.
In the second step, the HMT-STA-MB hybrid was prepared as follows: $0.2 \mathrm{~g}$ of the prepared HMT-STA hybrid was added to $40 \mathrm{~mL} \mathrm{MB}$ aqueous solution $\left(100 \mathrm{mg} \cdot \mathrm{L}^{-1}\right)$ and stirred. The obtained blue precipitate was filtrated and was washed with distilled water. In the third step, $0.2 \mathrm{~g}$ of MAC, prepared according to our previous work [28], was added with stirring to $10 \mathrm{~mL}$ suspension solution of the HMT-STA-MB hybrid. The obtained MAC-HMT-STA-MB composite was filtrated and dried at $100^{\circ} \mathrm{C}$. In any of the three steps, the mixtures were stirred at $500 \mathrm{rpm}$ speed by a magnetic agitator at ambient temperature for $3 \mathrm{~h}$.

\subsection{Photocatalytic Activity for Degradation of Dyes}

2.4.1. Photocatalytic with Sunlight. Solar photocatalytic experiments were performed in the Pyrex glass vessel containing $\left.30 \mathrm{~mL} \mathrm{MB} \mathrm{(40} \mathrm{mg.} \mathrm{L}^{-1}\right)$ and $13 \mathrm{mg}$ of the MACHMT-STA-MB composite. The solutions were irradiated under direct solar radiation in consecutive sunny days in July-August 2015 between 11 am and 3 pm (GPS coordinates: $\left.\mathrm{N}=32^{\circ} 29^{\prime}, \mathrm{E}=53^{\circ} 59^{\prime}\right)$. It should be noted that the solutions were not stirred during solar irradiation.

2.4.2. Photocatalytic with UV and Visible Sources. Photocatalytic degradation process was also carried out under UV and visible light irradiation. A $250 \mathrm{~W}$ high-pressure mercury lamp and a metal halide lamp (500 W, Philips) were used as UV and visible light sources, respectively. The $30 \mathrm{~mL}$ dye solution with $13 \mathrm{mg}$ of composite was stirred continuously in a $200 \mathrm{~mL}$ water-cooled cylindrical Pyrex vessel reactor. The UV light source was placed in the middle of the vessel. The visible light source was set about $10 \mathrm{~cm}$ from the liquid surface of the suspension. The reaction was initiated by switching on the light source after adding the composite to dye solutions. The reaction temperature was controlled at $27^{\circ} \mathrm{C}$ by recycling the cooling water in a water bath. During the process, at given time intervals, $4 \mathrm{~mL}$ of suspension was collected and then analyzed by a UV-Vis spectrophotometer after removing the composite.

The decolorization values of dye solutions were calculated by the following formula:

$$
D=\frac{C_{0}-C_{1}}{C_{0}} \times 100=\frac{A_{0}-A_{1}}{A_{0}} \times 100 \text {, }
$$

where $D$ is decolorization percent and $C_{0}, A_{0}$ and $C_{1}, A_{1}$ are the concentration and absorbance of dye solution at maximum wavelength before and after irradiation, respectively.

2.5. $M B$ Adsorption Experiments. Adsorption equilibrium experiments were carried out by adding 13-60 mg MACHMT-STA-MB into $50 \mathrm{~mL} \mathrm{MB}$ solution with different concentrations $\left(10-50 \mathrm{mg} \cdot \mathrm{L}^{-1}\right)$ at room temperature in the dark under stirring. The final concentration of $\mathrm{MB}$ was defined by the UV-Vis spectrometer at $664 \mathrm{~nm}$. The amount of MB adsorbed onto the sorbent in $\mathrm{mg} / \mathrm{g}$ was calculated using the following equation:

$$
q_{e}=\frac{\left(C_{0}-C_{e}\right) V}{m}
$$




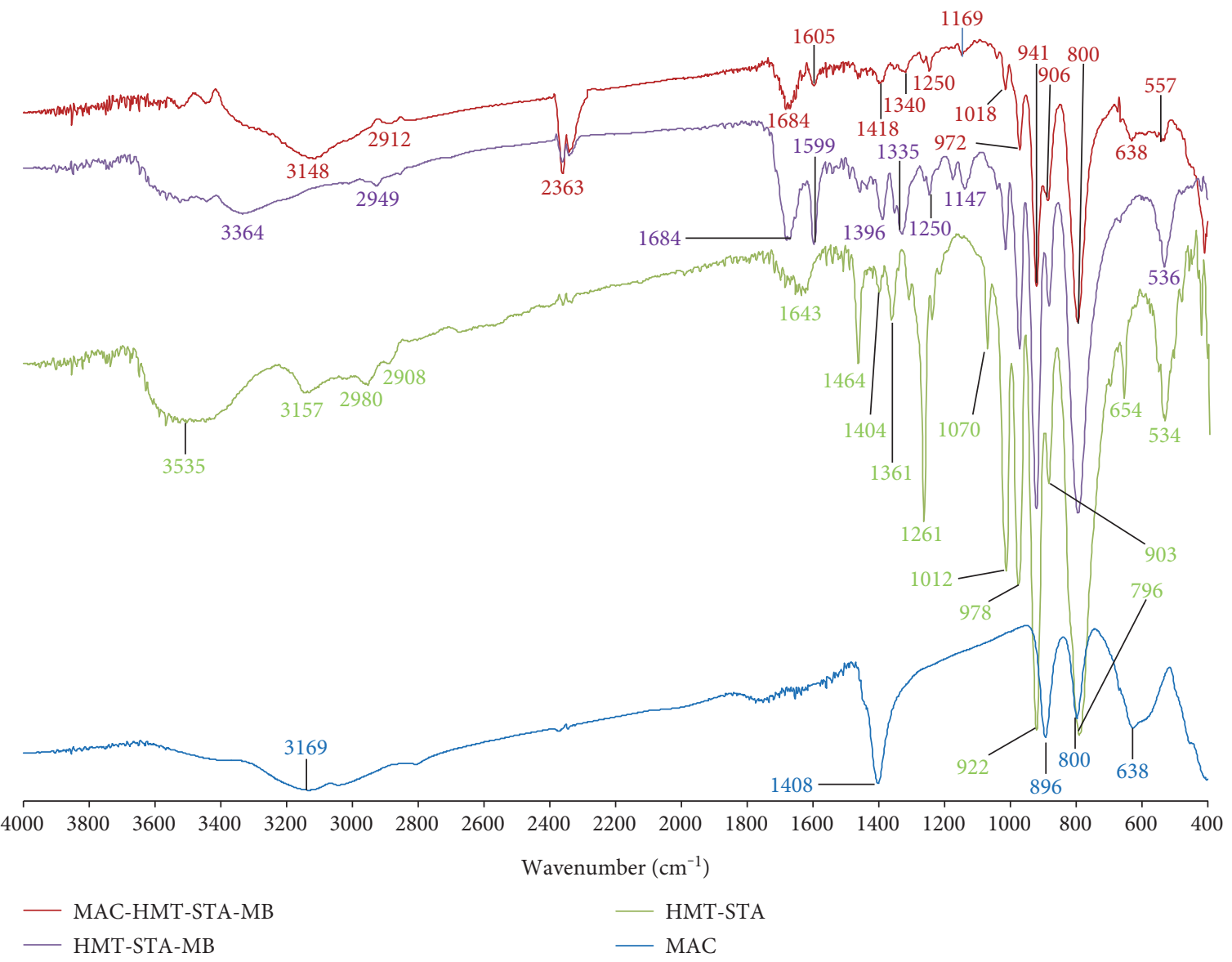

FIgURE 1: IR spectra of magnetic activated carbon (MAC), hexamine-silicotungstate hybrid (HMT-STA), hexamine-silicotungstatemethylene blue hybrid (HMT-STA-MB), and MAC-HMT-STA-MB nanoparticle.

where $C_{e}$ is the equilibrium concentration of $\mathrm{MB}$ in the solution in $\mathrm{mg} / \mathrm{L}, C_{0}$ is initial $\mathrm{MB}$ concentration in $\mathrm{mg} / \mathrm{L}, m$ is the amount of adsorbent mass in grams, and $V$ is the solution volume in $\mathrm{L}$.

Similar to two previous works [28,29], the isotherm model parameters were determined by nonlinear error functions minimizing using the solver add-in with Microsoft's spreadsheet, Excel. Chi-square statistic $\left(\chi^{2}\right)$ was used to evaluate the fitness of isotherm equations to the experimental data.

2.6. Kinetic Analysis. The kinetic analysis of decolorization was carried out using the pseudo first-order kinetics, $\ln \left(A_{0} /\right.$ $\left.A_{t}\right)=\ln \left(C_{0} / C_{t}\right)=k t$, where $A_{0}$ and $C_{0}$ are the initial absorbance and concentration of dye solution, respectively, $A_{t}$ and $C_{t}$ are the absorbance and concentration of dye solution at time $t$, and the slope $k$ is the kinetic constant in $\min ^{-1}$. All $C_{0} / C_{t}$ values were obtained by the maximum absorption in the whole absorption spectrum in order to plot $\ln \left(C_{0} / C_{t}\right)$ versus $t$.

\section{Results and Discussion}

3.1. Characterizations of Composite. The carbon, hydrogen, and nitrogen elemental analyses of the HMT-STA hybrid (C, 7.42\%; H, 1.33\%; and $\mathrm{N}, 5.74 \%$ ) reveal the attachment of seven hexamine molecules to STA and suggest the stoichiometric formula of $\left[\mathrm{C}_{6} \mathrm{H}_{13} \mathrm{~N}_{4}\right]_{7}\left[\mathrm{SiW}_{12} \mathrm{O}_{40}\right][\mathrm{HSi}$ $\left.\mathrm{W}_{12} \mathrm{O}_{40}\right] \cdot 3 \mathrm{H}_{2} \mathrm{O}$ for the HMT-STA hybrid. On the basis of this composition, the calculated elemental analyses are as follows: C, 7.43\%; H, 1.45\%; and N, 5.77\%.

The FTIR spectra of MAC, HMT-STA, HMT-STA-MB, and MAC-HMT-STA-MB are shown in Figure 1. The IR spectrum of MAC-HMT-STA-MB composite exhibits the characteristic bands of the HMT-STA-MB hybrid and of MAC. The strong absorption peaks at $1100-750 \mathrm{~cm}^{-1}$ show the presence of $\mathrm{SiW}_{12} \mathrm{O}_{40}{ }^{4-}$ anions with the $\alpha$-Keggin structure. The peaks at $795,885,970$, and $920 \mathrm{~cm}^{-1}$ are attributed to the stretching modes of the corner sharing of $\mathrm{W}-\mathrm{O}_{\mathrm{c}}-\mathrm{W}$, edge sharing of $\mathrm{W}-\mathrm{O}_{\mathrm{b}}-\mathrm{W}$, terminal $\mathrm{W}-\mathrm{O}_{\mathrm{d}}$, and $\mathrm{Si}-\mathrm{O}$, respectively $[25,30]$. The peak at about $1260 \mathrm{~cm}^{-1}$ can be attributed to vibration of the $\mathrm{CH}_{2}$ of HMT [31-33]. The peak at $1595 \mathrm{~cm}^{-1}$ corresponds to the vibration of the aromatic ring of MB [34]. The 795, 893, and $1400 \mathrm{~cm}^{-1}$ peaks of MAC overlap with other peaks, and only $623 \mathrm{~cm}^{-1}$ peak appears in the composite without overlapping.

Scanning electron microscopy (SEM) was used to characterize the morphology of the composite material. The SEM image of MAC-HMT-STA-MB (Figures 2(a), 2(b), and 2(c)) shows that the morphology is similar to that of the bare MAC support [28] and POM hybrid has indwelled in pores. The specific surface area, total pore volume, and mean pore 


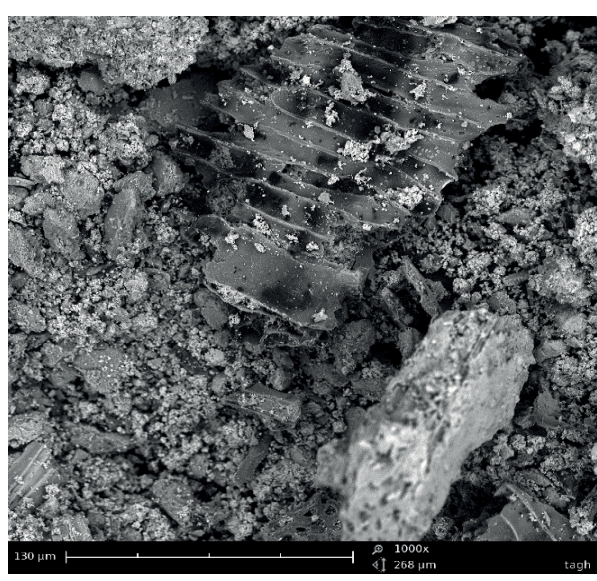

(a)

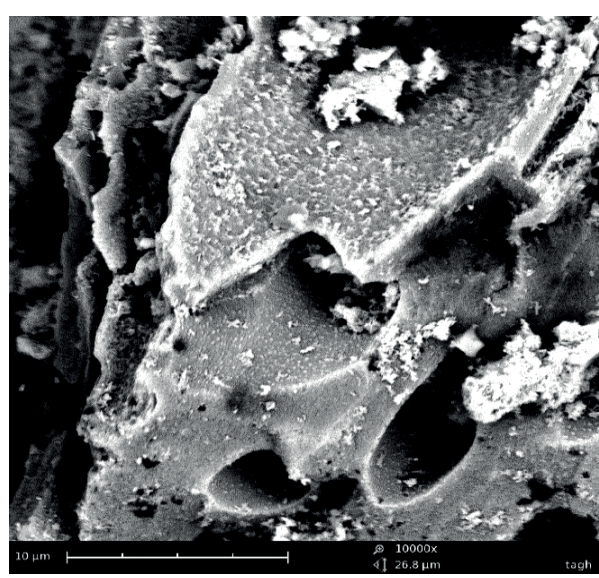

(c)

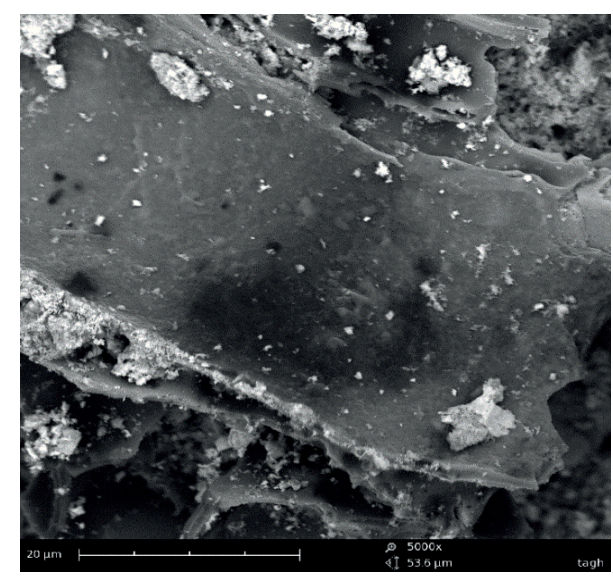

(b)

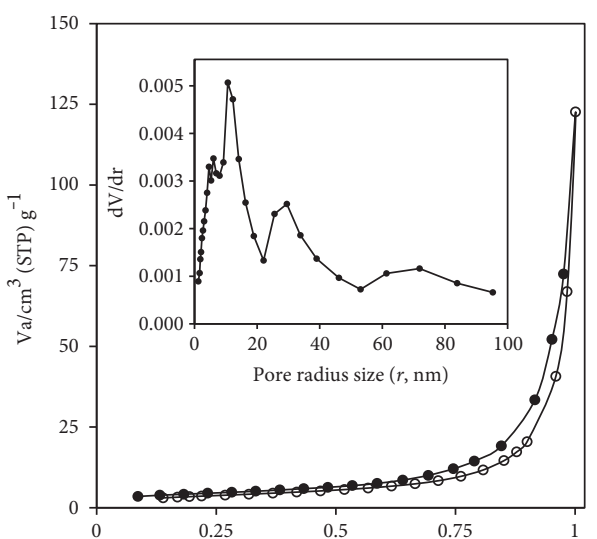

(d) $P / P_{0}$

Figure 2: SEM images of MAC-HMT-STA-MB. (a) 1000x, (b) 5000x, (c) 10000x, and (d) $\mathrm{N}_{2}$ adsorption-desorption isotherm and pore size distribution.

diameter of the MAC-HMT-STA-MB were measured using the BET method with $\mathrm{N}_{2}$ adsorption-desorption isotherms (Figure 2(d)). The specific surface area of the composite was $13.180 \mathrm{~m}^{2} / \mathrm{g}$, which is lower than that of MAC $\left(54.451 \mathrm{~m}^{2} / \mathrm{g}\right)$. This difference can be explained by the fact that the pores are filled by the HMT-STA-MB hybrid. The mean pore diameter and total pore volume were $40.992 \mathrm{~nm}$ and $0.1351 \mathrm{~cm}^{3} \mathrm{~g}^{-1}$, respectively. According to the IUPAC classification, the mentioned mean pore diameter belongs to the mesopore groups. Moreover, $\mathrm{N}_{2}$ adsorption-desorption isotherm is classified as type IV according to the IUPAC classification, indicating that the MAC-HMT-STA-MB structure is mesoporous [35].

In order to confirm the solid structure of the hybrid, the powder X-ray diffraction (XRD) patterns of HMT-STA and MAC-HMT-STA-MB are collected in Figure 3(a). The positions of the sharp peaks below $2 \theta=10^{\circ}$ can be ascribed to $\mathrm{SiW}_{12} \mathrm{O}_{40}^{4-}$ of the HMT-STA hybrid. The typical peaks at $2 \theta=21.04^{\circ}, 35.48^{\circ}, 45.68^{\circ}, 53.16^{\circ}, 55.20^{\circ}, 58.96^{\circ}$, and $62.96^{\circ}$ are from MAC $[8,28,36,37]$. Therefore, the primary structure of POM has remained intact in the solid structure of composite.
The TG and DSC curves of the MAC-HMT-STA$\mathrm{MB}$ composite are shown in Figure 3(b). Based on the formula of the HMT-STA hybrid and the MAC composition (65\% $\mathrm{Fe}_{3} \mathrm{O}_{4}, 25 \%$ carbon, and $10 \% \mathrm{H}_{2} \mathrm{O} \quad[28]$ ), the stoichiometric formula of the composite is proposed to be $\mathrm{C}_{7} \mathrm{Fe}_{3} \mathrm{O}_{4}\left[\mathrm{C}_{6} \mathrm{H}_{13} \mathrm{~N}_{4}\right]_{7}\left[\mathrm{C}_{16} \mathrm{H}_{18} \mathrm{~N}_{3} \mathrm{~S}\right]_{3}\left[\mathrm{SiW}_{12} \mathrm{O}_{40}\right][\mathrm{HSi}$ $\left.\mathrm{W}_{12} \mathrm{O}_{40}\right] \mathrm{Cl}_{3}$ and thermal curves can be well interpreted. The first weight loss of $5.19 \%$ and the exothermic peak at ca. $100-270^{\circ} \mathrm{C}$ are ascribed to the loss of three hexamine molecules attached to $\mathrm{HSiW}_{12} \mathrm{O}_{40}{ }^{3-}$ (calculated value is 5.28\%). These weak binding HMT molecules are easily detached from the composite and then decomposed. It has been reported that the hexamine and its complexes are sublimated with decomposition at atmospheric pressure about $230-290^{\circ} \mathrm{C}$ [38-40]. Then, the strong binding HMT molecules (i.e., four hexamine molecules attached to $\mathrm{SiW}_{12} \mathrm{O}_{40}{ }^{4-}$ ) are released and then decomposed. Therefore, the second weight loss of $7.01 \%$ and the exothermic peak at $305^{\circ} \mathrm{C}$ is corresponding to these HMT molecules (calculated loss value is $7.04 \%$ ). The third weight loss of $11.66 \%$ and the exothermic peak at $541^{\circ} \mathrm{C}$ is related to the decomposition of three $\mathrm{MB}$ molecules attracted to 


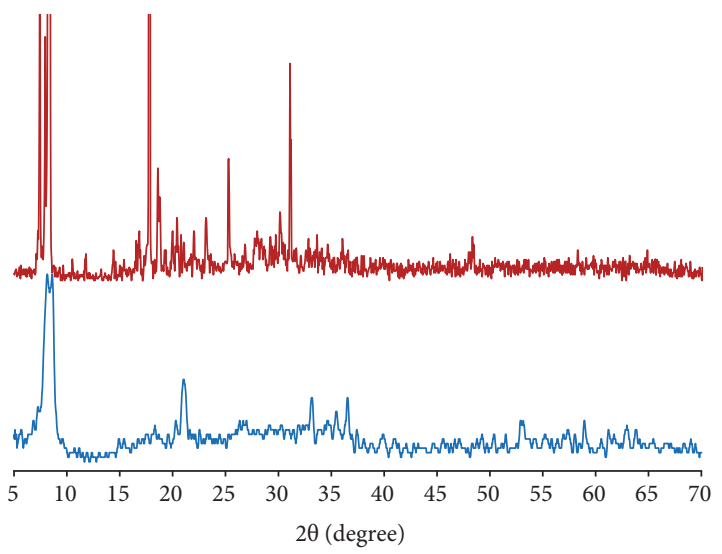

— HMT-STA

— MAC-HMT-STA-MB

(a)

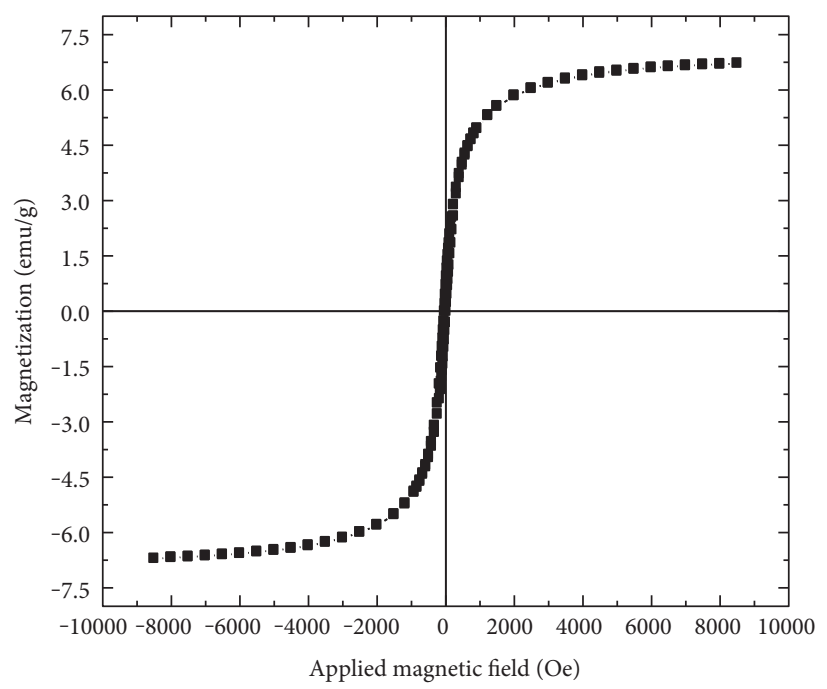

(c)

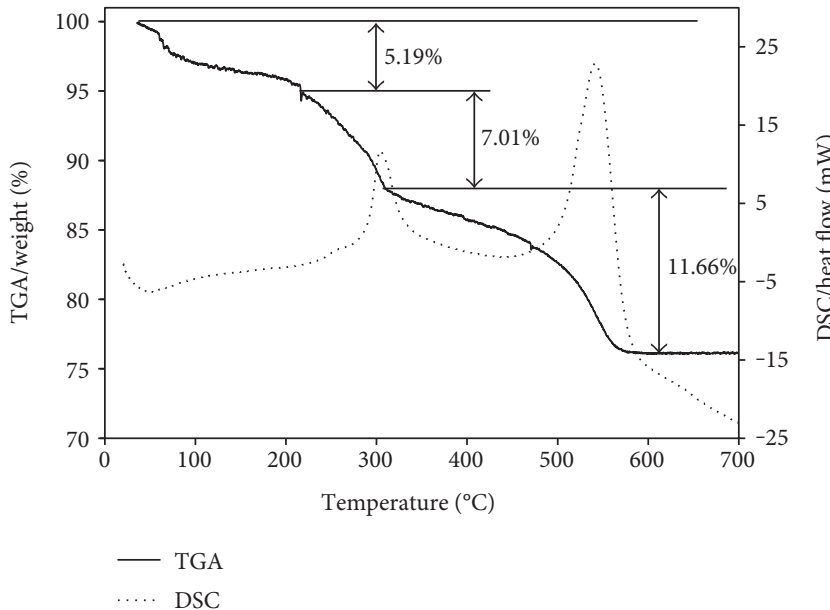

(b)

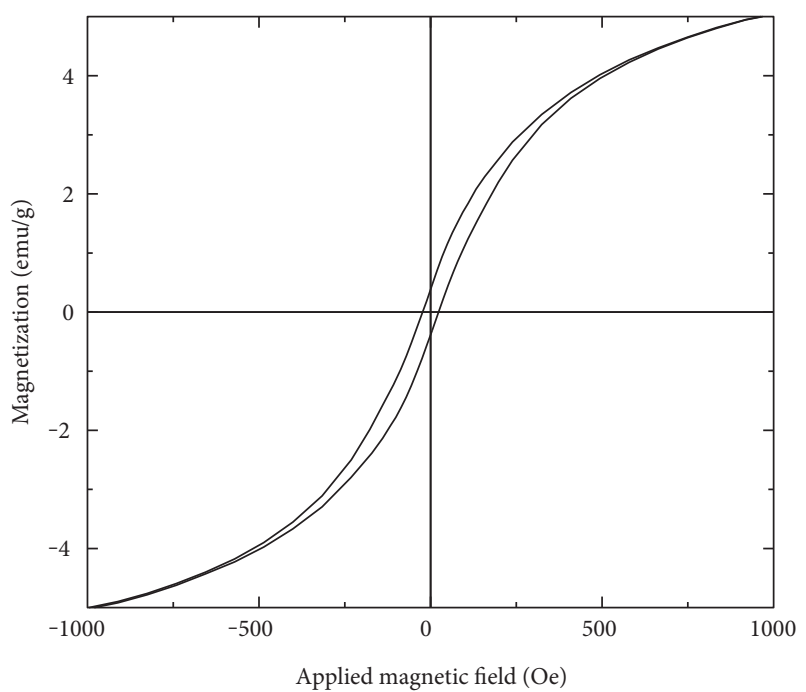

(d)

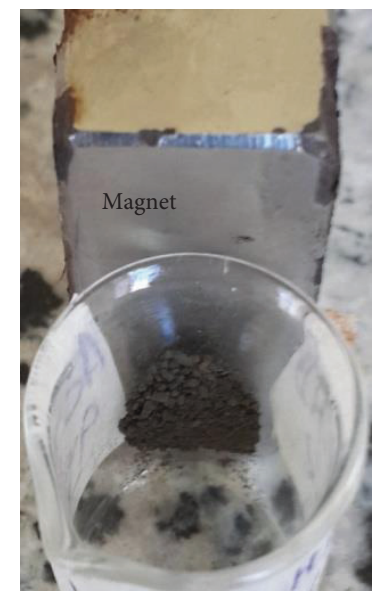

(e)

Figure 3: (a) X-ray diffraction patterns of HMT-STA hybrid and MAC-HMT-STA-MB composite, (b) TGA and DSC curves, (c, d) magnetization curve, and (e) photograph of magnetic property of MAC-HMT-STA-MB. 


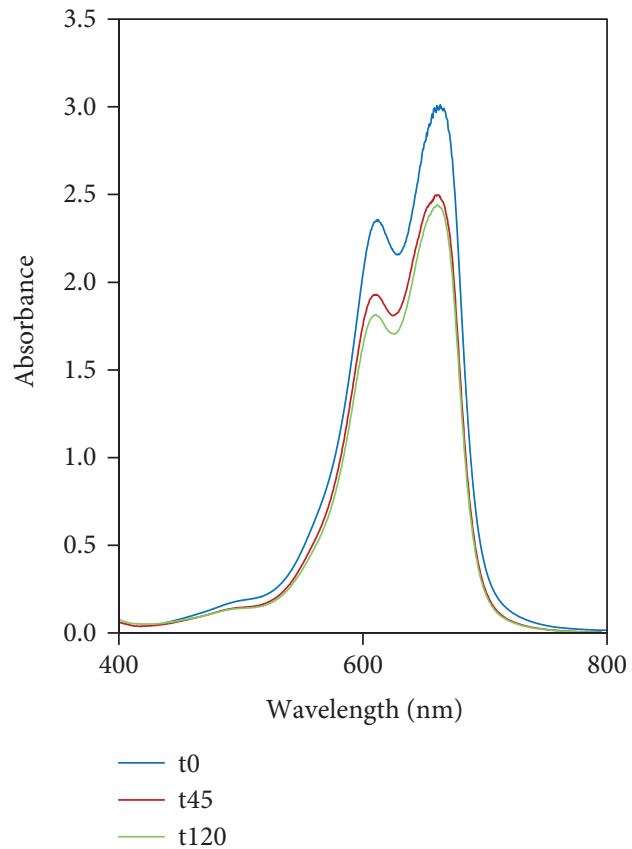

(a)

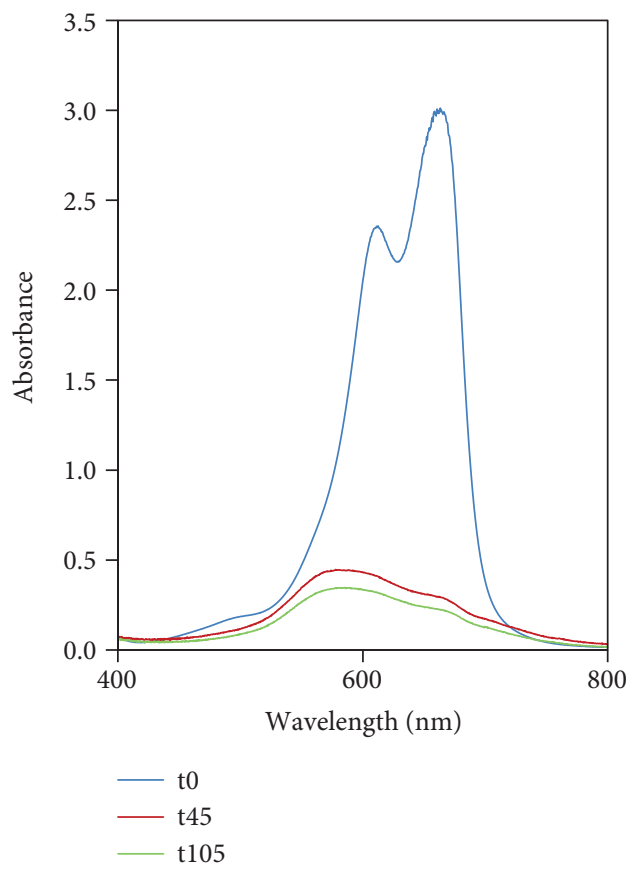

(c)

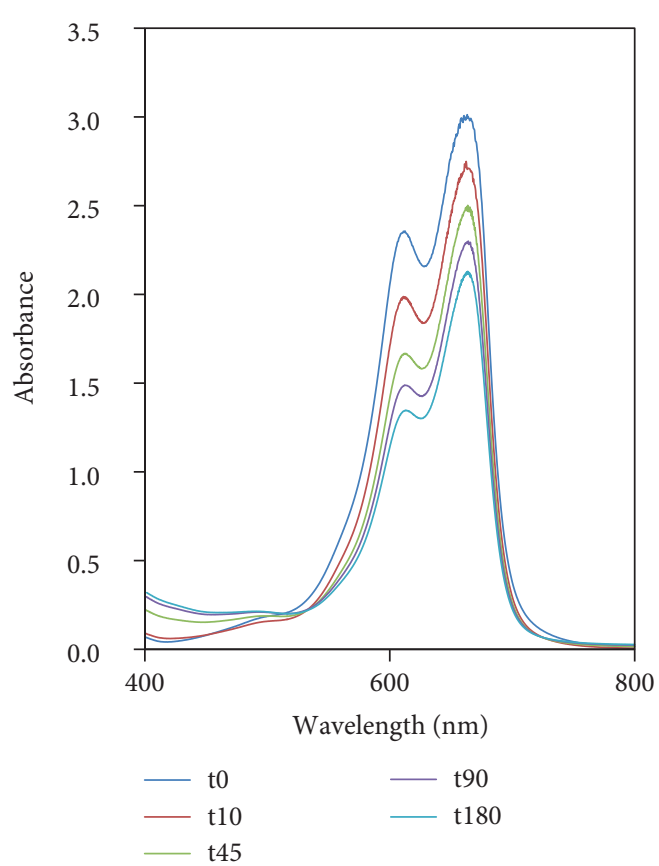

(b)

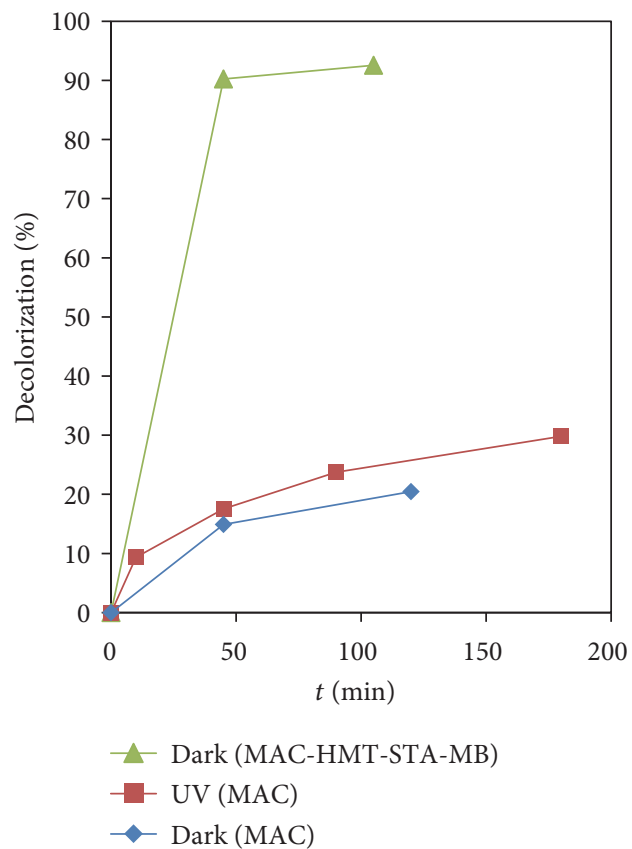

(d)

Figure 4: UV-Vis absorption spectra of MB $(20 \mathrm{mg} / \mathrm{L}, 50 \mathrm{~mL})$ during the adsorption on MAC $(0.5 \mathrm{~g} / \mathrm{L})$ in the dark (a), the photodegradation under UV (b), the adsorption on MAC-HMT-STA-MB (0.5 g/L) in the dark (c), and changes in decolorization versus time (d).

the HMT-STA hybrid, the oxidation of the carbon [28], and the decomposition of silicotungstate to $\mathrm{WO}_{3}$ and $\mathrm{SiO}_{2}$ at about $550^{\circ} \mathrm{C}$ [41] (calculated loss value is $11.68 \%$ ). The whole weight loss of $23.86 \%$ is compatible with the calculated value $(24.00 \%)$.

The magnetic characterization of MAC-HMT-STA-MB and its enlargement near the origin are shown in Figures 3(c) and 3(d). As can be seen, the resultant composite has superparamagnetic behavior with saturation magnetization (Ms) of $6.7 \mathrm{emu} / \mathrm{g}$ (in the magnetic field equal to $\pm 8.5 \mathrm{kOe}$ ). Figure 3(e) shows that the particles of the composite can be attracted by an external magnet. The Ms of the composite has dropped as compared with MAC ( $\mathrm{Ms}=34.6 \mathrm{emu} / \mathrm{g}$ [28]) due to the inclusion of POM hybrid coating. 


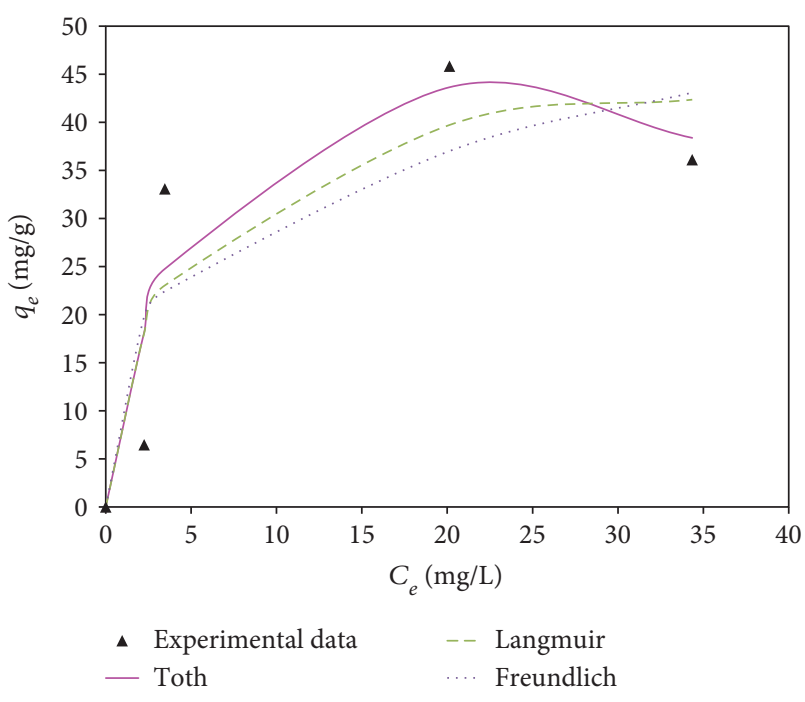

FIgure 5: The Langmuir, Freundlich, and Toth isotherms for the adsorption of MB by MAC-HMT-STA-MB.

3.2. Composite Activity for Removal and Degradation of $M B$. In the first, the efficiency of the composite for the wastewater treatment was evaluated by removal and degradation of $\mathrm{MB}$. Before the photocatalytic degradation, adsorption of $\mathrm{MB}$ on the composite was evaluated. The adsorption of $\mathrm{MB}$ has been reported by MAC containing different iron oxide values $[8,11]$. It has been proven that the affinity of MAC to cationic dyes is much higher than that to anionic dyes. Hence, the MAC has been coated with HMT-STA-MB instead of HMT-STA because the surface charge of HMTSTA is negative due to the existence of silicotungstate. However, the affinity of MAC-HMT-STA-MB toward $\mathrm{MB}$ molecules is high despite the HMT-STA-MB coating so that it demonstrated high adsorption capacity for $\mathrm{MB}$ (Figure 4(c)) much higher than MAC (Figure 4(a)). Despite the adsorbed $\mathrm{MB}$ on the surface of the composite, it is yet negative due to the existence of silicotungstate with high electronegative oxygens. Therefore, the interaction between these polyoxoanions and the cationic dye molecules makes a good adsorption toward MB molecules. To further study, the adsorption isotherm of $\mathrm{MB}$ adsorbed onto the composite was recorded. The most common isotherms for describing solid-liquid sorption systems are the Langmuir, the Freundlich, and the Toth isotherms. Figure 5 shows the experimental adsorption isotherms for MB/MAC-HMTSTA-MB system along with the curve fitted by isotherm models. The isotherm parameters and values of chi-square are also shown in Table 1. Examination of isotherm plots (Figure 5) shows that the Toth isotherm more accurately describes the sorption behavior of $\mathrm{MB}$ on MAC-HMTSTA-MB due to exhibiting the lowest value of $\chi^{2}$. The adsorption data obeyed the Toth model exhibiting heterogeneous surface conditions and monolayer adsorption. Therefore, the adsorbate has a high affinity for the surface at low surface coverage. However, as coverage increases, the affinity of the adsorbate for the surface decreases (Figure 5). The order of adsorption of isotherm models for $\mathrm{MB}$ is
TABLE 1: Parameters of the isotherm models for the adsorption of $\mathrm{MB}$ onto MAC-HMT-STA-MB.

\begin{tabular}{|c|c|c|c|c|}
\hline Model & Equation & Parameter & Value & $\chi^{2}$ \\
\hline Toth & $q_{e}=\frac{K_{t} C_{e}}{\left(a_{t}+C_{e}\right)^{1 / t}}$ & $\begin{array}{c}K_{t} \\
a_{t} \\
1 / t\end{array}$ & $\begin{array}{c}5003.196 \\
18.564 \\
2.118\end{array}$ & 10.571 \\
\hline Langmuir & $q_{e}=\frac{q_{m} K_{a} C_{e}}{1+K_{a} C_{e}}$ & $\begin{array}{l}q_{m} \\
K_{a}\end{array}$ & $\begin{array}{c}46.734 \\
0.281\end{array}$ & 13.729 \\
\hline Freundlich & $q_{e}=K_{F} C_{e}^{1 / n}$ & $\begin{array}{l}K_{F} \\
1 / n\end{array}$ & $\begin{array}{c}15.746 \\
0.285\end{array}$ & 17.325 \\
\hline
\end{tabular}

Toth $>$ Langmuir $>$ Freundlich. This order is identical with the sorption behavior of MB on HMT-STA [33].

The composite was then tested as a catalyst for the photocatalytic degradation of MB. While the MAC shows very low photocatalytic activity toward $\mathrm{MB}$ degradation under UV light (Figure 4(b)), the MAC-HMT-STA-MB is very active (Figure 6(d)). Compared to adsorption (Figure 6(a)), photocatalytic degradation with MAC-HMTSTA-MB displays higher kinetic constant $(k)$ and removal efficiency (Figures 6(b), 6(c), 6(d), and 6(e)). The kinetic constants of MB $(40 \mathrm{mg} / \mathrm{L})$ removal in the solar, visible, and UV photocatalytic process with composite $(0.44 \mathrm{~g} / \mathrm{L})$ are $11.5,10.1$, and 9.9 times higher than that in the adsorption process, respectively (Figure 6(f)).

3.3. Photocatalytic Activity for RhB Degradation. To further explore the activity of the composite, it was applied for photodecomposition of $\mathrm{RhB}$ under sunlight irradiation. Before the photocatalytic degradation of $\mathrm{RhB}$, the adsorption process was studied in aqueous solution $(\mathrm{pH}=$ without adjustment $=7.4)$. MAC-HMT-STA-MB cannot adsorb $\mathrm{RhB}$ because $\mathrm{RhB}\left(\mathrm{pK}_{\mathrm{a}}=3.1\right)$ is as neutral form in $\mathrm{pH} 7.4$ (Figure 7(a)).

3.4. Photocatalytic Activity for Mixture of $M B$ and $R h B$. The real wastewater can not only contain a single component. Hence, the mixture of $\mathrm{MB}$ and $\mathrm{RhB}$ was selected to explore the ability of the composite in the degradation of mixed dye molecules. The adsorption experiment (Figure 7(b)) shows that the absorption peak of MB molecules quickly disappeared, just leaving the characteristic absorption peak of $\mathrm{RhB}$. The photodegradation was also performed. Figure 7(c) shows the spectra of the mixed solution of $\mathrm{MB}$ and $\mathrm{RhB}$ during the photodegradation under sunlight irradiation in the presence of $0.44 \mathrm{~g} / \mathrm{L}$ of the composite in $\mathrm{pH} 7.6$ (without adjustment). The spectra clearly confirm that the composite degrades both $\mathrm{MB}$ and $\mathrm{RhB}$ dyes, but the rate and percent of $\mathrm{RhB}$ decolorization are lower than those of MB. It is interesting that the light is able to degrade $\mathrm{RhB}$ in the mixed solutions in the presence of the composite, while it could not degrade alone RhB (RhB solution after adsorption experiment (Figure 7(a)) was irradiated with UV light and was not observed any change). Because MAC-HMTSTA-MB has a surface negative charge, the cationic MB molecules are preferentially adsorbed on it. Then, the surface of the hybrid possessing a slightly positive charge does 

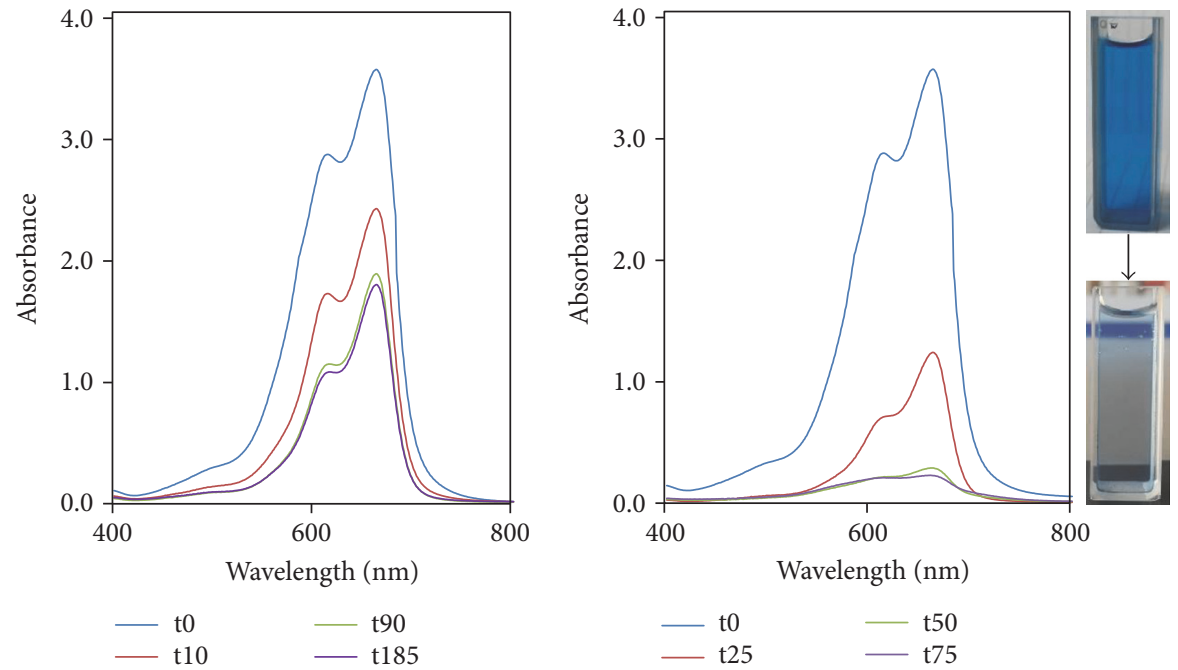

(b)
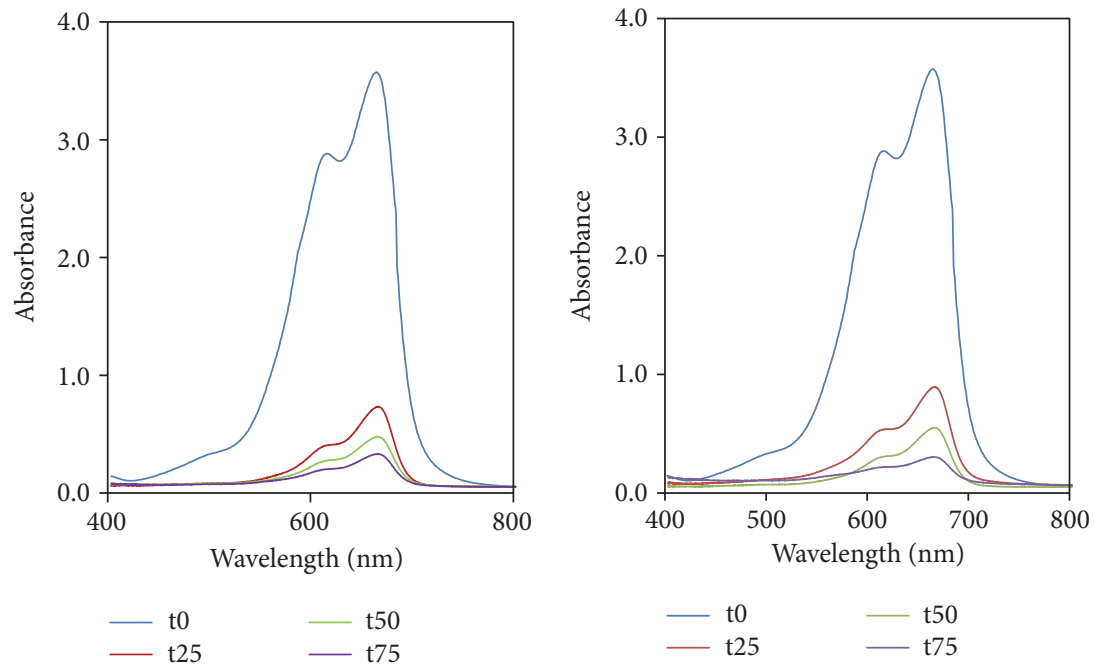

(c)

(d)
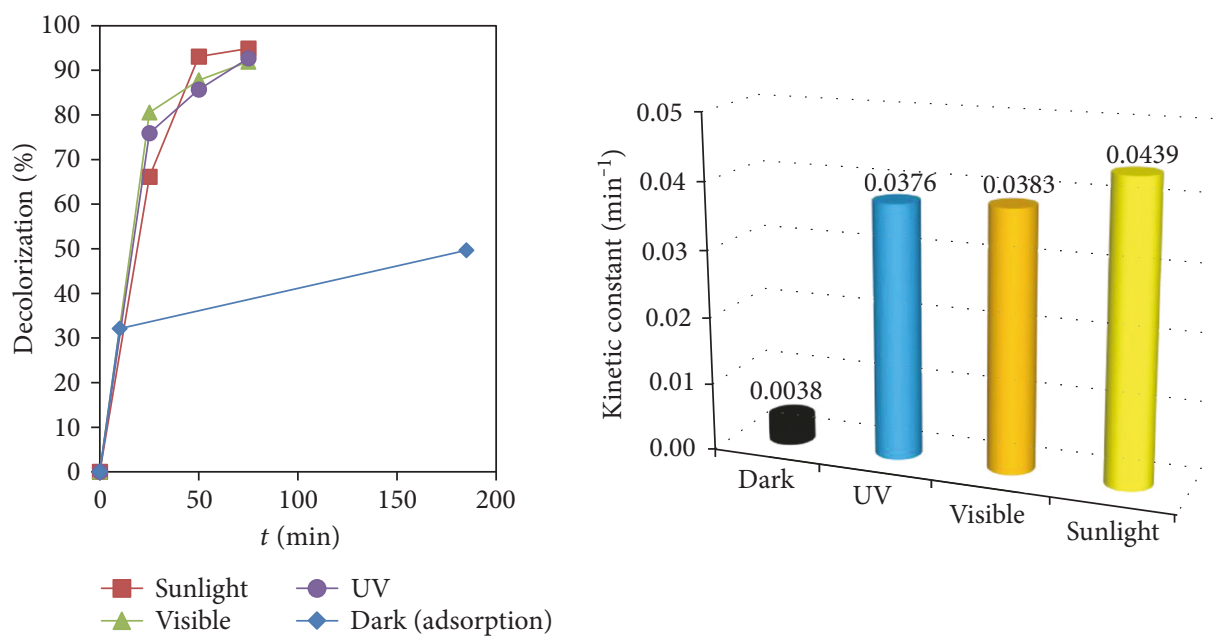

(e)

(f)

Figure 6: UV-Vis absorption spectra of MB $(40 \mathrm{mg} / \mathrm{L}, 30 \mathrm{~mL})$ during the adsorption on MAC-HMT-STA-MB (0.44 g/L) in the dark (a), during the photodegradation under sunlight and corresponding digital image of solution before and after irradiation (b), visible (c), UV (d), changes in decolorization versus time (e), and their kinetic constants (f). 


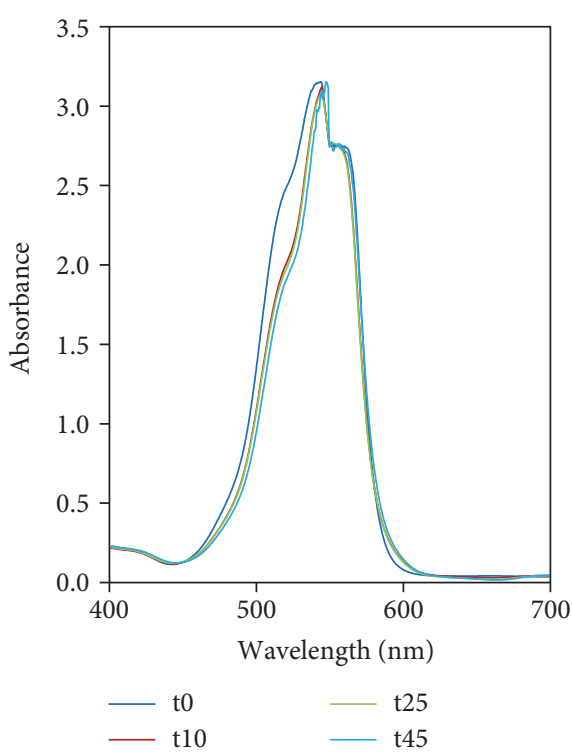

(a)

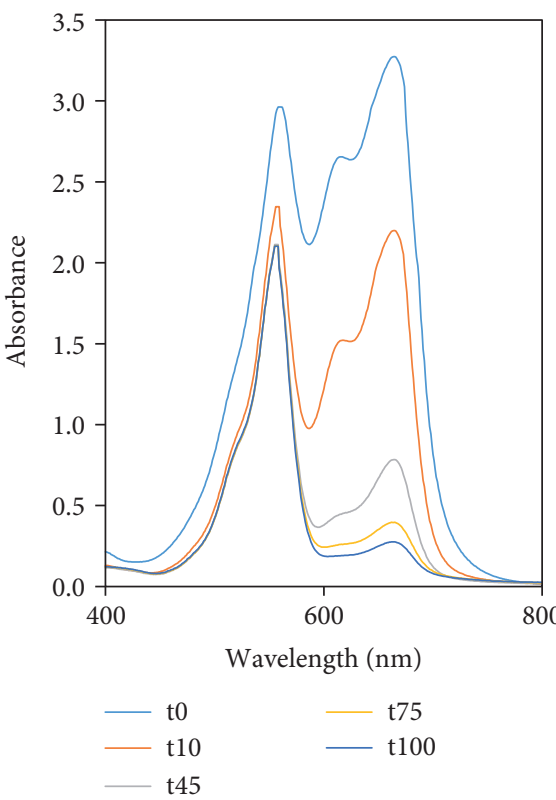

(c)

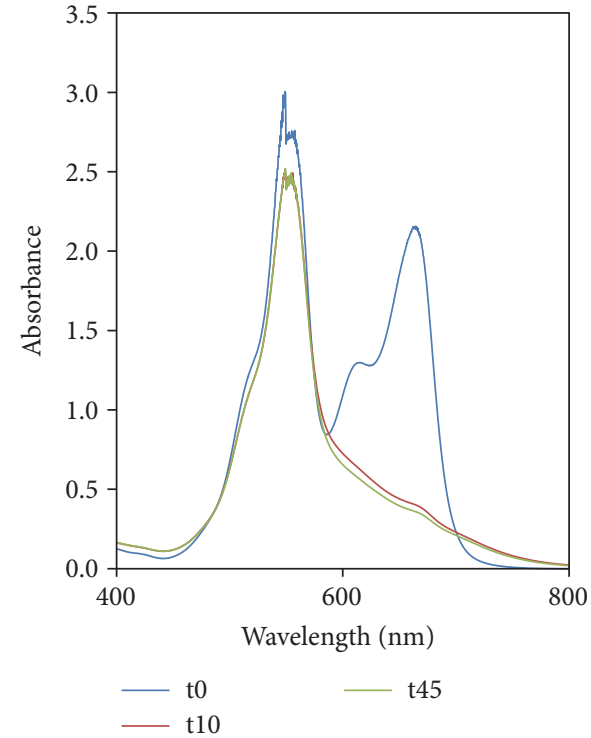

(b)

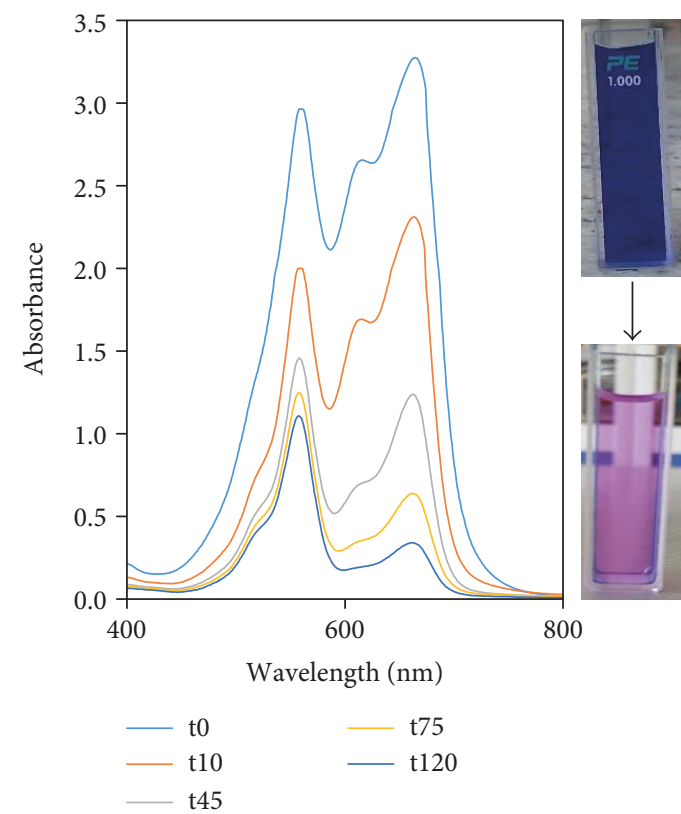

(d)

Figure 7: UV-Vis absorption spectra of $\mathrm{RhB}(20 \mathrm{mg} / \mathrm{L}, 20 \mathrm{~mL}, \mathrm{pH}=$ without adjustment $=7.4)$ (a) and the mixed solution of RhB and $\mathrm{MB}$ (each dye $10 \mathrm{mg} / \mathrm{L}$, total volume $=40 \mathrm{~mL}, \mathrm{pH}=$ without adjustment) (b) during the adsorption on $0.47 \mathrm{~g} / \mathrm{L}$ and $0.23 \mathrm{~g} / \mathrm{L}$ of $\mathrm{MAC}-\mathrm{HMT}$ STA-MB, respectively, in the dark; spectra of the mixed solution of $\mathrm{RhB}(8 \mathrm{mg} / \mathrm{L})$ and $\mathrm{MB}(45 \mathrm{mg} / \mathrm{L}$, total volume $=50 \mathrm{~mL})$ during the photodegradation under sunlight in the presence of the MAC-HMT-STA-MB $(0.44 \mathrm{~g} / \mathrm{L}$ ) in the $\mathrm{pH}=7.6$ (without adjustment) (c) and $\mathrm{pH}=2.5(\mathrm{~d})$ and corresponding digital images of the mixed solutions before and after irradiation.

not adsorb the neutral $\mathrm{RhB}$ molecules. Indeed, the lower uptake of RhB decreases the efficiency of degradation. For this reason, the decreasing of $\mathrm{pH}$ increases the efficiency of its degradation (Figure $7(\mathrm{~d})$ ) because $\mathrm{RhB}$ is as anionic form in $\mathrm{pH} 2.5$.

3.5. Composite Activity for MO Solution. To further investigation, MAC-HMT-STA-MB was applied for MO solution. Before the photocatalytic degradation of $\mathrm{MO}$, the adsorption process was studied in aqueous solution $(\mathrm{pH}=$ without adjustment $=4.5)$. MO cannot adsorb on the composite because it is as anionic form in $\mathrm{pH} 4.5$ (Figure $8(\mathrm{a})$ ).

3.6. Photocatalytic Activity for Mixture of $M B$ and MO. To further confirm whether MAC-HMT-STA-MB has the ability to separate $\mathrm{MB}$ dye from mixed dye solution, the mixture of $\mathrm{MB}$ and $\mathrm{MO}$ was prepared and used. Figure 8(b) shows the adsorption experiment of the mixed solution of 


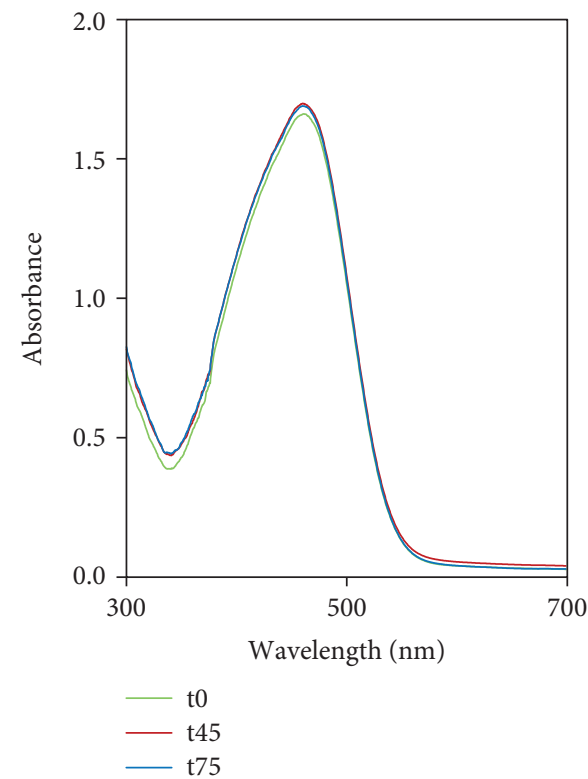

(a)

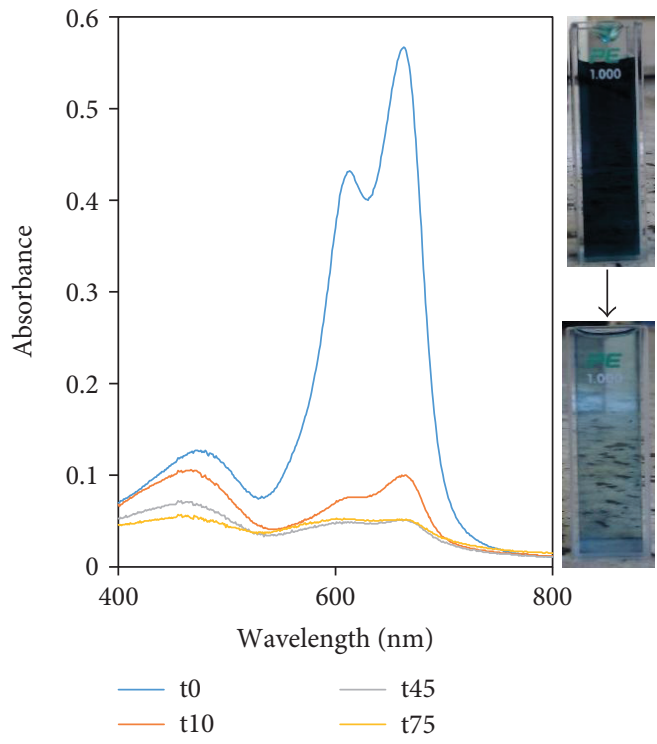

(c)

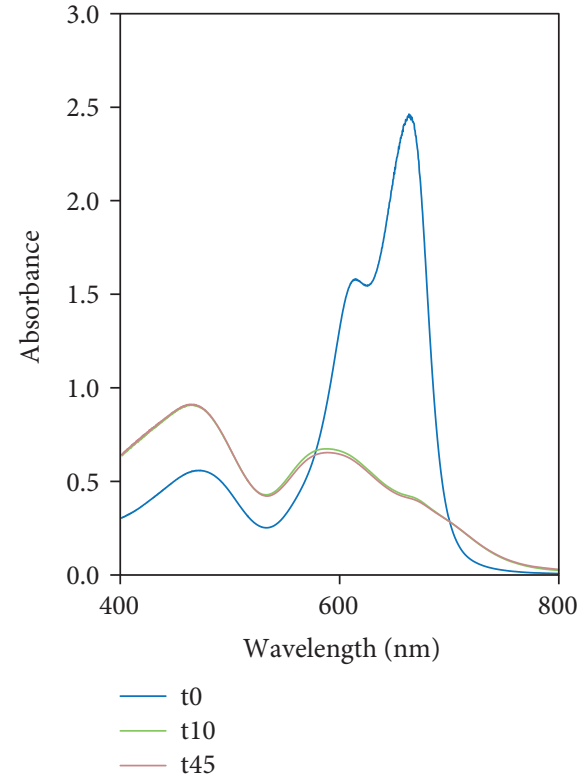

(b)

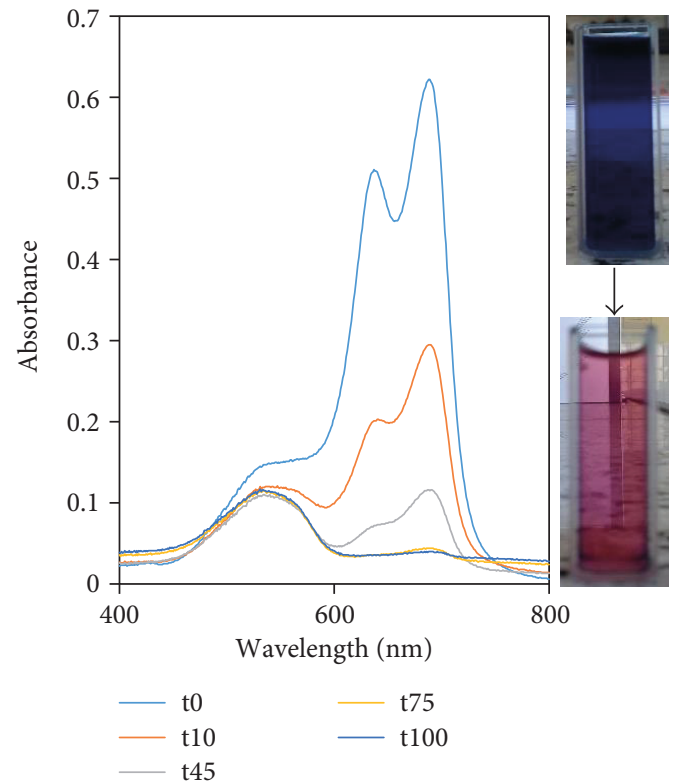

(d)

FIGURE 8: UV-Vis absorption spectra of $\mathrm{MO}(20 \mathrm{mg} / \mathrm{L}, 20 \mathrm{~mL}, \mathrm{pH}=$ without adjustment $=4.5)(\mathrm{a})$ and the mixed solution of $\mathrm{MO}$ and $\mathrm{MB}$ (each dye $10 \mathrm{mg} / \mathrm{L}$, total volume $=40 \mathrm{~mL}, \mathrm{pH}=$ without adjustment $=6.3$ ) (b) during the adsorption on $0.65 \mathrm{~g} / \mathrm{L}$ and $0.32 \mathrm{~g} / \mathrm{L}$ of $\mathrm{MAC}$ HMT-STA-MB, respectively, in the dark; spectra of the mixed solution of $\mathrm{MO}(16 \mathrm{mg} / \mathrm{L})$ and $\mathrm{MB}(45 \mathrm{mg} / \mathrm{L}$, total volume $=50 \mathrm{~mL})$ during the photodegradation under sunlight in the presence of the MAC-HMT-STA-MB $(0.44 \mathrm{~g} / \mathrm{L}$ ) in the $\mathrm{pH}=8.2$ (without adjustment) (c) and $\mathrm{pH}=2.5(\mathrm{~d})$ and corresponding digital images of the mixed solutions before and after irradiation. Note: in all experiments, the absorbance was measured in a $10 \mathrm{~mm}$ cell except the mixed solution of $\mathrm{MO}(16 \mathrm{mg} / \mathrm{L})$ and $\mathrm{MB}(45 \mathrm{mg} / \mathrm{L})$ (c and d) that were measured in a $1 \mathrm{~mm}$ cell.

$\mathrm{MB}$ and $\mathrm{MO}$ in the presence of $0.32 \mathrm{~g} / \mathrm{L}$ of the composite in pH 6.3 (without adjustment). The spectra show the quick adsorption of $\mathrm{MB}$ and remaining of $\mathrm{MO}$. The photodegradation was also performed. Figure 8(c) shows the spectra of the mixed solutions of MB and MO during the photodegradation under sunlight irradiation in the presence of $0.44 \mathrm{~g} / \mathrm{L}$ of the composite in $\mathrm{pH} 8.2$ (without adjustment).
The spectra clearly confirm that the composite degrades both MB and MO dyes. It is interesting that the light is able to degrade $\mathrm{MO}$ in the mixed solution in the presence of the composite, while it could not degrade alone MO (MO solution after adsorption experiment (Figure 8(a)) was irradiated with UV light and was not observed any change). Because MAC-HMT-STA-MB has a surface negative charge, 
the cationic MB molecules are preferentially adsorbed on it. Then, the surface of the hybrid possessing a slightly positive charge adsorbs the anionic MO molecules. Indeed, the higher adsorption of MO increases the efficiency of its degradation. For this reason, the decreasing of $\mathrm{pH}$ to 2.5 decreases the efficiency of degradation (Figure $8(\mathrm{~d})$ ) because $\mathrm{MO}$ is as neutral form in $\mathrm{pH} 2.5$.

3.7. Outline of Photodegradation Mechanism. The photodegradation mechanism takes place through dye-sensitized degradation. Dye-sensitized degradations take place in cases where there exists an interaction between dye and photocatalyst [42]. Particularly, favorable conditions are encountered in the present situation due to both species (POM and $\mathrm{MB}$ ) which exist in the adsorbed state. Therefore, the process of degradation involves absorption of light by the MB molecules followed by charge injection into the HMT-STA moiety of the composite and then oxidative degradation of adsorbed dye. A proposed photodegradation mechanism is deduced that absorption of light $(h v)$ by the MAC-HMTSTA-MB generates the excited state of the POM hybrid moiety $\left([\mathrm{HMT}-\mathrm{STA}-\mathrm{MB}]^{*}\right)$ :

$$
\text { MAC-HMT-STA-MB }+h v \rightarrow \text { MAC-[HMT-STA-MB] }{ }^{*}
$$

This excited state of the hybrid results from the oxygen to metal charge transfer band of STA [24]. The $[\text { HMT-STA-MB }]^{*}$ is a strong oxidant able to oxidize and, most often, mineralize organic dyes. There are two pathways through which the excited HMT-STA reduced: reaction with excited organic dye in aqueous solution (reactions (4) and (5)):

$$
\begin{aligned}
\text { Dye }+h v & \rightarrow \text { Dye }^{*} \\
{[\text { HMT-STA-MB }]^{*}+\text { Dye }^{*} } & \rightarrow[\text { HMT-STA-MB }]\left(e^{-}\right)+\text {Dye }^{+\bullet}
\end{aligned}
$$

$$
\begin{aligned}
\text { Dye }^{+\bullet} \rightarrow & \text { decomposition into } \\
& \text { colorless products }
\end{aligned}
$$

and reaction through formation of ${ }^{\bullet} \mathrm{OH}$ radicals from the reaction with $\mathrm{H}_{2} \mathrm{O}[43]$ :

$$
[\text { HMT-STA-MB }]^{*}+\mathrm{H}_{2} \mathrm{O} \rightarrow[\mathrm{HMT}-\mathrm{STA}-\mathrm{MB}]\left(e^{-}\right)+{ }^{\bullet} \mathrm{OH}+\mathrm{H}^{+}
$$

The organic dye is oxidized directly (reaction (6)) and indirectly by ${ }^{\circ} \mathrm{OH}$ radicals generated in reaction (7). The reduced hybrid can be reoxidized by reduction of dye:

$$
\begin{aligned}
{[\text { HMT-STA-MB }]\left(e^{-}\right)+\text {Dye } \rightarrow } & {[\text { HMT-STA-MB }] } \\
& + \text { reduction products }
\end{aligned}
$$

As it was confirmed, the uptake of $\mathrm{MB}, \mathrm{RhB}$, and $\mathrm{MO}$ on the composite is high, relatively low, and very low, respectively. In the same way, the photodegradation of the ternary mixed solution of them conform to this trend (Figure 9). The higher photodegradation of $\mathrm{RhB}$ and $\mathrm{MO}$ in the mixed

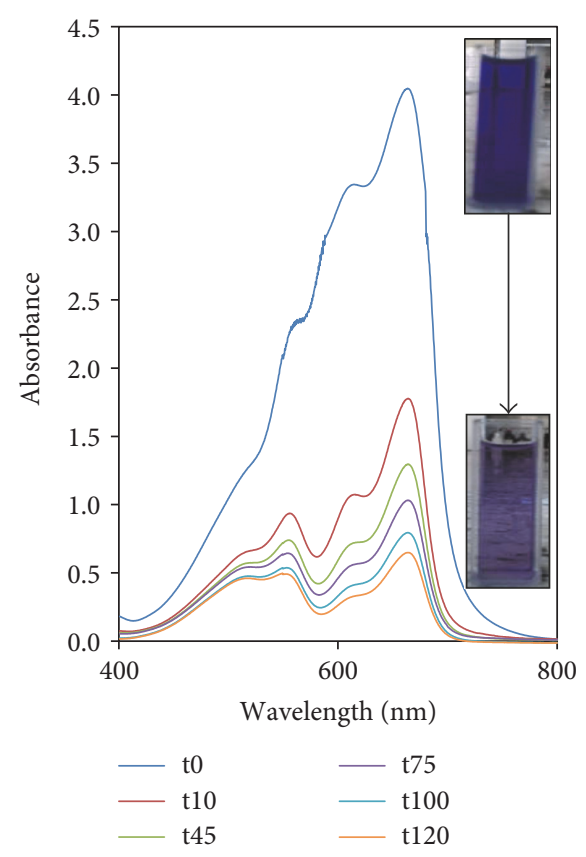

FIGURE 9: UV-Vis absorption spectra of the mixed solution of $\mathrm{MO}$ $(4 \mathrm{mg} / \mathrm{L}), \mathrm{RhB}(4 \mathrm{mg} / \mathrm{L})$, and $\mathrm{MB}(45 \mathrm{mg} / \mathrm{L}$, total volume $=50 \mathrm{~mL})$ during the photodegradation under sunlight in the presence of the MAC-HMT-STA-MB $(0.44 \mathrm{~g} / \mathrm{L})$ in the $\mathrm{pH}=2.5$ and corresponding digital images of the mixed solution before and after irradiation.

solution with $\mathrm{MB}$ is due to higher uptake of them on the surface of the composite after uptake of MB.

3.8. The Reusability of Magnetic Nanophotocatalyst. The reusability and stability of the catalysts are important characteristics in catalytic technology considering economic feasibility. After adsorption-photodegradation experiments, the MAC-HMT-STA-MB nanoparticles can be isolated from the solution using a magnet. To test the release ability of $\mathrm{MB}$ adsorbed, various eluting solutions were added such as pure water, pure ethanol solution, and the mixed solution of $\mathrm{NaCl}$ with ethanol/methanol and water. Results (Figure 10(a)) show that the MB molecules on MAC-HMTSTA-MB are released faster in the solution of $\mathrm{NaCl}$ with methanol and $\mathrm{H}_{2} \mathrm{O}$ than other solutions. It should be noted that all adsorbed $\mathrm{MB}$ molecules cannot be released into the solution during one elution. The successive elution cycles are needed for releasing all $\mathrm{MB}$ molecules. The reusability of the composite was tested by adsorption of $20 \mathrm{mg} / \mathrm{L} \mathrm{MB}$ solution on once eluted MAC-HMT-STA-MB. The result (Figure 10(b)) indicated that the adsorption ability of the composite remains, and hence, it can be reused for removal cycle of dye.

3.9. Comparison with Other STA-Immobilized Catalysts. To compare the photocatalytic efficiency of the MAC-HMTSTA-MB composite with other STA-immobilized catalysts reported in the literature, we have summarized the results in Table 2. The advantages of the present magnetic nanophotocatalyst are that it does not use expensive organic moieties 


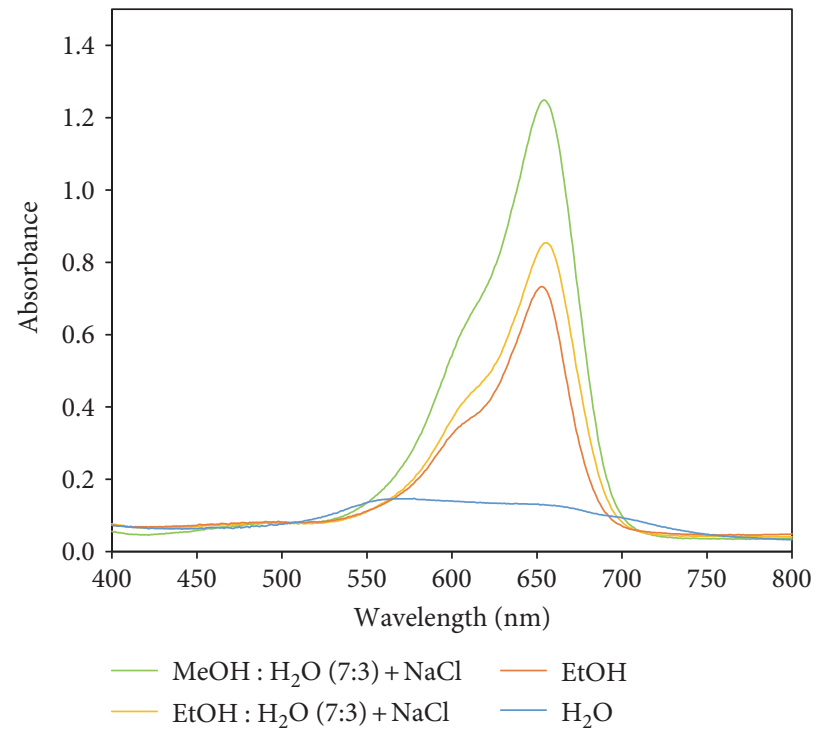

(a)

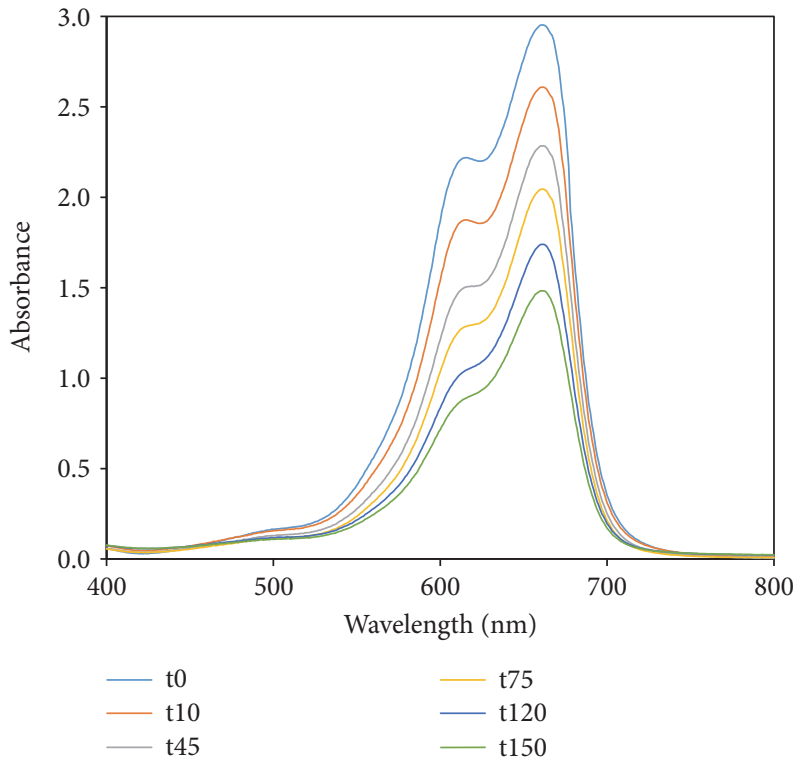

(b)

Figure 10: The UV-Vis spectra of desorbed MB solution from MB@MAC-HMT-STA-MB using various elution solutions (a) and UV-Vis spectra of MB (20 mg/L, $30 \mathrm{~mL})$ during the adsorption on eluted MAC-HMT-STA-MB $(0.25 \mathrm{~g} / \mathrm{L})$ with ethanol (b).

TABLE 2: Comparison of photodegradation of MB, MO, and RhB by using STA, different STA-immobilized catalysts reported in the literature, and MAC-HMT-STA-MB.

\begin{tabular}{|c|c|c|c|c|c|c|}
\hline Catalysts & Light & $\mathrm{C}_{\text {dye }}(\mathrm{mg} / \mathrm{L})$ & $\begin{array}{c}\text { Catalyst dosage } \\
(\mathrm{g} / \mathrm{L})\end{array}$ & $\begin{array}{l}\text { Time } \\
(\mathrm{min})\end{array}$ & $\begin{array}{c}\text { Decolorization } \\
(\%)\end{array}$ & Ref. \\
\hline $\mathrm{SiW}_{12} \mathrm{O}_{40}{ }^{4-}$ (homogeneous catalyst) & UV & MB (10) & 0.17 & 90 & 98.5 & {$[44]$} \\
\hline $\mathrm{SiW}_{12} \mathrm{O}_{40}{ }^{4-}$ (homogeneous catalyst) & Vis. & $\mathrm{MO}(4.5)^{\mathrm{a}}$ & 8.89 & 140 & 21 & {$[25]$} \\
\hline $\mathrm{H}_{4} \mathrm{SiW}_{12} \mathrm{O}_{40}$ (powder) & UV & MO (10) & 1 & 30 & 4.6 & {$[45]$} \\
\hline $\mathrm{H}_{4} \mathrm{SiW}_{12} \mathrm{O}_{40}$ & Vis. & $\operatorname{RhB}(10)$ & 1 & 480 & 45 & {$[46]$} \\
\hline $\mathrm{H}_{4} \mathrm{SiW}_{12} \mathrm{O}_{40} / \mathrm{PVA}$ & Vis. & $\operatorname{RhB}(10)$ & 1 & 480 & 74 & {$[46]$} \\
\hline $\mathrm{H}_{4} \mathrm{SiW}_{12} \mathrm{O}_{40} / \mathrm{PVA} / \mathrm{Ag}$ & Vis. & $\operatorname{RhB}(10)$ & 1 & 480 & 100 & {$[46]$} \\
\hline$\left(\mathrm{C}_{16} \mathrm{H}_{36} \mathrm{~N}\right)_{4}\left(\mathrm{SiW}_{12} \mathrm{O}_{40}\right)$-PVDF & UV & MO (15) & $2+1.5 \mathrm{mM} \mathrm{H}_{2} \mathrm{O}_{2}$ & 510 & $97^{\mathrm{a}}$ & [47] \\
\hline$\left(\mathrm{SiW}_{12} \mathrm{O}_{40}\right)_{30 \%}$-zeolite $\left(\mathrm{NH}_{4} \mathrm{Y}\right)$ & UV & MO (26) & $0.5+0.9 \mathrm{~L} / \mathrm{min}$ air & 240 & 73 & {$[48]$} \\
\hline$\left(\mathrm{SiW}_{12} \mathrm{O}_{40}\right)_{30 \%}$-zeolite (ZSM5) & UV & MO (26) & $0.5+0.9 \mathrm{~L} / \mathrm{min}$ air & 240 & 75 & {$[48]$} \\
\hline $\mathrm{Ag} @ \mathrm{Ag}_{4} \mathrm{SiW}_{12} \mathrm{O}_{40}$ & Vis. & MO (20) & 1.25 & 5 & 100 & [49] \\
\hline MFNs@SiO $2 @ \mathrm{Ag}_{4} \mathrm{SiW}_{12} \mathrm{O}_{40} / \mathrm{Ag}$ & Vis. & $\mathrm{MB}(3.2)$ & 0.5 & 10 & $90^{\mathrm{a}}$ & {$[50]$} \\
\hline $\mathrm{SiW}_{12} \mathrm{O}_{40}-\mathrm{PANI}-\mathrm{SnO}_{2}$ & Vis. $^{\text {b }}$ & $\mathrm{RhB}(4.8)$ & 20 & 60 & $100^{\mathrm{a}}$ & {$[51]$} \\
\hline $\mathrm{H}_{4} \mathrm{SiW}_{12} \mathrm{O}_{40} / \mathrm{PVA} / \mathrm{PMMA}$ & UV & MO (10) & $1^{\mathrm{c}}$ & 30 & 95.1 & {$[45]$} \\
\hline $\mathrm{H}_{4} \mathrm{SiW}_{12} \mathrm{O}_{40} / \mathrm{PVA}$ & UV & MO (10) & $1^{\mathrm{c}}$ & 30 & 75.2 & {$[45]$} \\
\hline $\mathrm{H}_{4} \mathrm{SiW}_{12} \mathrm{O}_{40} / \mathrm{PMMA}$ & UV & MO (10) & $1^{\mathrm{c}}$ & 30 & 13.8 & {$[52]$} \\
\hline $\mathrm{H}_{4} \mathrm{SiW}_{12} \mathrm{O}_{40} / \mathrm{PA} 6$ & UV & MO (10) & 5 & 30 & 99.3 & [53] \\
\hline $\mathrm{H}_{4} \mathrm{SiW}_{12} \mathrm{O}_{40} / \mathrm{TiO}_{2} / \mathrm{K}_{2} \mathrm{Ti}_{6} \mathrm{O}_{13}$ & UV & MO (10) & 1 & 70 & $50^{\mathrm{a}}$ & {$[54]$} \\
\hline MAC-HMT-STA-MB & Solar/Vis./UV & MB (40) & 0.44 & 75 & 94.9/91.9/92.7 & This work \\
\hline MAC-HMT-STA-MB & Solar & $\mathrm{MB}(45)+\mathrm{RhB}(8)$ & 0.44 & 120 & $90.1+63.8$ & This work \\
\hline MAC-HMT-STA-MB & Solar & $\mathrm{MB}(45)+\mathrm{MO}(16)$ & 0.44 & 75 & $91.0+59.0$ & This work \\
\hline
\end{tabular}

${ }^{a}$ Value was estimated from original figure of the reference; ${ }^{b}$ high-voltage $250 \mathrm{~W} \mathrm{Hg} \mathrm{lamp;}{ }^{c}\left[\mathrm{H}_{4} \mathrm{SiW}_{12} \mathrm{O}_{40}\right]=1 \mathrm{~g} / \mathrm{L}$. PVDF = poly(vinylidene fluoride); MFNs = magnesium ferrite nanoparticles; PANI = polyaniline; PVA = poly(vinyl alcohol); PMMA = poly (methyl methacrylate); PA6 = polycaprolactam. 
(see footnotes of Table 2) in the catalyst preparation, has higher rate of decolorization, and shows photocatalytic behavior under visible and sunlight besides UV light.

\section{Conclusions}

In summary, a heterogeneous POM-based nanocomposite was successfully prepared by immobilization of the HMTSTA-MB hybrid on magnetic activated carbon nanoparticles as support. It exhibited photocatalytic activity in the degradation of $\mathrm{MB}, \mathrm{RhB}$, and $\mathrm{MO}$ organic dyes and their binary mixtures under sunlight, visible, or UV irradiation. The dyes are removed via combination of adsorption and photocatalytic degradation under light. The sunlight is able to degrade $\mathrm{RhB}$ and $\mathrm{MO}$ in the mixed solution in the presence of the composite, while it does not degrade alone $\mathrm{RhB}$ and MO. The degradation of the dyes proceeds through dye-sensitized degradation.

This study proves that immobilization of POM species on MAC increases catalytic activity and facilitates separation from the solution by using an external magnetic field.

\section{Conflicts of Interest}

The author declares that there is no conflict of interest regarding the publication of this paper.

\section{Acknowledgments}

The author expresses his appreciation to the Payame Noor University and Sina Chemical Industries Company for the support of this study.

\section{References}

[1] K. Hunger, Industrial Dyes: Chemistry, Properties, Applications, John Wiley \& Sons, 2007.

[2] E. Forgacs, T. Cserháti, and G. Oros, "Removal of synthetic dyes from wastewaters: a review," Environment International, vol. 30, pp. 953-971, 2004.

[3] S. K. Giri, N. N. Das, and G. C. Pradhan, "Synthesis and characterization of magnetite nanoparticles using waste iron ore tailings for adsorptive removal of dyes from aqueous solution," Colloid Surface Physicochemal Engineering Aspect, vol. 389, pp. 43-49, 2011.

[4] P. Hu, Y. Zhang, K. Tong et al., "Removal of organic pollutants from red water by magnetic-activated coke," Desalination and Water Treatment, vol. 54, pp. 2710-2722, 2014.

[5] T. Jiang, Y.-d. Liang, Y.-j. He, and Q. Wang, "Activated carbon/ $/ \mathrm{NiFe}_{2} \mathrm{O}_{4}$ magnetic composite: a magnetic adsorbent for the adsorption of methyl orange," Journal of Environmental Chemical Engineering, vol. 3, pp. 1740-1751, 2015.

[6] T. Madrakian, A. Afkhami, M. Ahmadi, and H. Bagheri, "Removal of some cationic dyes from aqueous solutions using magnetic-modified multi-walled carbon nanotubes," Journal of Hazardous Materials, vol. 196, pp. 109-114, 2011.

[7] H. R. Rajabi, H. Arjmand, S. J. Hoseini, and H. Nasrabadi, "Surface modified magnetic nanoparticles as efficient and green sorbents: synthesis, characterization, and application for the removal of anionic dye," Journal of Magnetism and Magnetic Materials, vol. 394, pp. 7-13, 2015.
[8] N. Yang, S. Zhu, D. Zhang, and S. Xu, "Synthesis and properties of magnetic $\mathrm{Fe}_{3} \mathrm{O}_{4}$-activated carbon nanocomposite particles for dye removal," Materials Letters, vol. 62, pp. 645-647, 2008.

[9] B. Zargar, H. Parham, and A. Hatamie, "Fast removal and recovery of amaranth by modified iron oxide magnetic nanoparticles," Chemosphere, vol. 76, pp. 554-557, 2009.

[10] Z. Zhang and J. Kong, "Novel magnetic $\mathrm{Fe}_{3} \mathrm{O}_{4} @ \mathrm{C}$ nanoparticles as adsorbents for removal of organic dyes from aqueous solution," Journal of Hazardous Materials, vol. 193, pp. 325-329, 2011.

[11] B. Zargar, H. Parham, and M. Rezazade, "Fast removal and recovery of methylene blue by activated carbon modified with magnetic iron oxide nanoparticles," Journal of the Chinese Chemical Society, vol. 58, pp. 694-699, 2011.

[12] M. L. Fetterolf, H. V. Patel, and J. M. Jennings, "Adsorption of methylene blue and acid blue 40 on titania from aqueous solution," Journal of Chemical \& Engineering Data, vol. 48, pp. 831-835, 2003.

[13] A. Afkhami, M. Saber-Tehrani, and H. Bagheri, "Modified maghemite nanoparticles as an efficient adsorbent for removing some cationic dyes from aqueous solution," Desalination, vol. 263, pp. 240-248, 2010.

[14] S. Song, Y. Ma, H. Shen, M. Zhang, and Z. Zhang, "Removal and recycling of ppm levels of methylene blue from an aqueous solution with graphene oxide," RSC Advances, vol. 5, pp. 27922-27932, 2015.

[15] S.-T. Yang, S. Chen, Y. Chang, A. Cao, Y. Liu, and H. Wang, "Removal of methylene blue from aqueous solution by graphene oxide," Journal of Colloid and Interface Science, vol. 359, pp. 24-29, 2011.

[16] F. Li, Y. Chen, H. Huang, W. Cao, and T. Li, "Removal of rhodamine $\mathrm{B}$ and $\mathrm{Cr}(\mathrm{VI})$ from aqueous solutions by a polyoxometalate adsorbent," Chemical Engineering Research and Design, vol. 100, pp. 192-202, 2015.

[17] F. Liu, S. Chung, G. Oh, and T. S. Seo, "Three-dimensional graphene oxide nanostructure for fast and efficient water-soluble dye removal," ACS Applied Materials \& Interfaces, vol. 4, pp. 922-927, 2012.

[18] X. Liu, J. Luo, Y. Zhu, Y. Yang, and S. Yang, "Removal of methylene blue from aqueous solutions by an adsorbent based on metal-organic framework and polyoxometalate," Journal of Alloys and Compounds, vol. 648, pp. 986-993, 2015.

[19] T. Madrakian, A. Afkhami, H. Mahmood-Kashani, and M. Ahmadi, "Adsorption of some cationic and anionic dyes on magnetite nanoparticles-modified activated carbon from aqueous solutions: equilibrium and kinetics study," Journal of the Iranian Chemical Society, vol. 10, pp. 481-489, 2013.

[20] S. Omwoma, C. T. Gore, Y. Ji, C. Hu, and Y.-F. Song, "Environmentally benign polyoxometalate materials," Coordination Chemistry Reviews, vol. 286, pp. 17-29, 2015.

[21] E. I. García-López, G. Marcì, and L. Palmisano, Heteropolyacid-Based Heterogeneous Photocatalysts for Environmental Application, in: Heterogeneous Photocatalysis, pp. 63-107, Springer, Berlin Heidelberg, 2016.

[22] J. Gómez-Pastora, S. Dominguez, E. Bringas, M. J. Rivero, I. Ortiz, and D. D. Dionysiou, "Review and perspectives on the use of magnetic nanophotocatalysts (MNPCs) in water treatment," Chemical Engineering Journal, vol. 310, pp. 407-427, 2017. 
[23] H. Bagheri, A. Afkhami, and A. Noroozi, "Removal of pharmaceutical compounds from hospital wastewaters using nanomaterials: a review," Analytical and Bioanalytical Chemistry Research, vol. 3, pp. 1-18, 2016.

[24] A. Dolbecq, P. Mialane, B. Keita, and L. Nadjo, "Polyoxometalate-based materials for efficient solar and visible light harvesting: application to the photocatalytic degradation of azo dyes," Journal of Materials Chemistry, vol. 22, pp. 24509-24521, 2012.

[25] W. Wang and S. Yang, "Photocatalytic degradation of organic dye methyl orange with phosphotungstic acid," Journal of Water Resource and Protection, vol. 2, p. 979, 2010.

[26] H. Kim, J. C. Jung, and I. K. Song, "Chemical immobilization of heteropolyacid catalyst on inorganic mesoporous material for use as an oxidation catalyst," Catalysis Surveys from Asia, vol. 11, pp. 114-122, 2007.

[27] J.-J. Ye and C.-D. Wu, "Immobilization of polyoxometalates in crystalline solids for highly efficient heterogeneous catalysis," Dalton Transactions, vol. 45, pp. 10101-10112, 2016.

[28] M. Taghdiri, N. Zamani, and S. A. Mousavian, "Study of hexamine removal by activated carbon modified with magnetic iron oxide nanoparticles for application in treatment of hexamine industrial wastewater," Desalination and Water Treatment, vol. 56, pp. 3323-3333, 2015.

[29] M. Taghdiri and N. Zamani, "Hexamine adsorption study on activated carbon from aqueous solutions for application in treatment of hexamine industrial wastewater," International Journal Environmental Science Technology, vol. 10, pp. 1926, 2013.

[30] Q. Zhai, L. Zhang, X. Zhao, H. Chen, D. Yin, and J. Li, "A novel iron-containing polyoxometalate heterogeneous photocatalyst for efficient 4-chlorophennol degradation by $\mathrm{H}_{2} \mathrm{O}_{2}$ at neutral pH," Applied Surface Science, vol. 377, pp. 17-22, 2016.

[31] J. O. Jensen, "Vibrational frequencies and structural determinations of hexamethylenetetraamine," Spectrochim Acta, Part A: Molecular and Biomolecular Spectroscopy, vol. 58, pp. 1347-1364, 2002.

[32] H. Mirhoseini and M. Taghdiri, "Extractive oxidation desulfurization of sulfur-containing model fuel using hexaminephosphotungstate hybrid as effective heterogeneous catalyst," Fuel, vol. 167, pp. 60-67, 2016.

[33] S. Mohammadghasemi-Samani and M. Taghdiri, "Facile synthesis of hexamine-silicotungstic acid hybrid and its photocatalytic activity toward degradation of dyes," International Journal Environmental Science and Technology, pp. 1-16, 2017.

[34] H. Yao, N. Li, S. Xu, J.-Z. Xu, J.-J. Zhu, and H.-Y. Chen, "Electrochemical study of a new methylene blue/silicon oxide nanocomposition mediator and its application for stable biosensor of hydrogen peroxide," Biosensors \& Bioelectronics, vol. 21, pp. 372-377, 2005.

[35] R. Francoise and R. Jean, Adsorption by Powders and Porous Solids, Methodology and Applications, in, Academic Press, London, Principles, 1999.

[36] N. Jaafarzadeh, B. Kakavandi, A. Takdastan, R. R. Kalantary, M. Azizi, and S. Jorfi, "Powder activated carbon $/ \mathrm{Fe}_{3} \mathrm{O}_{4}$ hybrid composite as a highly efficient heterogeneous catalyst for Fenton oxidation of tetracycline: degradation mechanism and kinetic," RSC Advances, vol. 5, pp. 84718-84728, 2015.

[37] H. Bagheri, A. A. Asgharinezhad, and H. Ebrahimzadeh, "Determination of trace amounts of $\mathrm{Cd}(\mathrm{II}), \mathrm{Cu}(\mathrm{II})$, and $\mathrm{Ni}(\mathrm{II})$ in food samples using a novel functionalized magnetic nanosorbent," Food Analytical Methods, vol. 9, pp. 876-888, 2016.

[38] E. A. Gusev, S. V. Dalidovich, and L. I. Krasovskaya, "Investigation of urotropine thermal decomposition reaction in self-generated atmosphere by means of thermal analysis method," Thermochimica Acta, vol. 93, pp. 21-24, 1985.

[39] A. Trzesowska and R. Kruszynski, "Channel-containing structure built of 3D sodium nitrate coordination polymer," Journal of Coordination Chemistry, vol. 61, pp. 2167-2177, 2008.

[40] G. Singh, B. P. Baranwal, I. P. S. Kapoor, D. Kumar, and R. Fröhlich, "Preparation, X-ray crystallography, and thermal decomposition of some transition metal perchlorate complexes of hexamethylenetetramine," The Journal of Physical Chemistry A, vol. 111, pp. 12972-12976, 2007.

[41] L. Zhang, H. Chen, X. Zhao et al., "The marriage of ferrocene and silicotungstate: an ingenious heterogeneous Fenton-like synergistic photocatalyst," Applied Catalysis B: Environmental, vol. 193, pp. 47-57, 2016.

[42] C. Chen, W. Zhao, P. Lei, J. Zhao, and N. Serpone, "Photosensitized degradation of dyes in polyoxometalate solutions versus $\mathrm{TiO} 2$ dispersions under visible-light irradiation: mechanistic implications," Chemistry-A European Journal, vol. 10, pp. 1956-1965, 2004.

[43] C. Streb, "New trends in polyoxometalate photoredox chemistry: from photosensitisation to water oxidation catalysis," Dalton Transactions, vol. 41, pp. 1651-1659, 2012.

[44] X. L. Hao, Y. Y. Ma, W. Z. Zhou, H. Y. Zang, Y. H. Wang, and Y. G. Li, "Polyoxometalate-based entangled coordination networks induced by an extended bis (triazole) ligand," Chemistry Asian Journal, vol. 9, pp. 3633-3640, 2014.

[45] T. Li, Z. Zhang, W. Li, C. Liu, H. Zhou, and L. An, "Electrospinning preparation, characterization, and enhanced photocatalytic activity of an Silicotungstic acid $\left(\mathrm{H}_{4} \mathrm{SiW}_{12} \mathrm{O}_{40}\right) /$ poly (vinyl alcohol)/poly (methyl methacrylate) composite nanofiber membrane," Journal of Applied Polymer Science, vol. 133, no. 11, 2016.

[46] C. Sui, C. Li, X. Guo et al., "Facile synthesis of silver nanoparticles-modified $\mathrm{PVA} / \mathrm{H}_{4} \mathrm{SiW}_{12} \mathrm{O}_{40}$ nanofibers-based electrospinning to enhance photocatalytic activity," Applied Surface Science, vol. 258, pp. 7105-7111, 2012.

[47] H. Yang, B. Shan, and L. Zhang, “A new composite membrane based on Keggin polyoxotungstate/poly (vinylidene fluoride) and its application in photocatalysis," RSC Advances, vol. 4, pp. 61226-61231, 2014.

[48] C. L. Marchena, L. Lerici, S. Renzini, L. Pierella, and L. Pizzio, "Synthesis and characterization of a novel tungstosilicic acid immobilized on zeolites catalyst for the photodegradation of methyl orange," Applied Catalysis B: Environmental, vol. 188, pp. 23-30, 2016.

[49] H. Huang, X. Li, Z. Kang et al., “Tuning metal@metal salt photocatalytic abilities by different charged anions," Dalton Transactions, vol. 39, pp. 10593-10597, 2010.

[50] W. Tang, Y. Su, X. Wang, Q. Li, S. Gao, and J. K. Shang, "Synthesis of a superparamagnetic $\mathrm{MFNs@SiO}_{2} @ \mathrm{Ag}_{4-}$ $\mathrm{SiW}_{12} \mathrm{O}_{40} / \mathrm{Ag}$ composite photocatalyst, its superior photocatalytic performance under visible light illumination, and its easy magnetic separation," RSC Advances, vol. 4, p. 30090, 2014.

[51] H. Ma, C. Li, J. Yin et al., "Polyoxometalate enhances the photocatalytic performance of polyaniline $/ \mathrm{SnO}_{2}$ composites," Materials Letters, vol. 168, pp. 103-106, 2016. 
[52] T. Li, Z. Zhang, W. Li, C. Liu, J. Wang, and L. An, " $\mathrm{H}_{4} \mathrm{SiW}_{12} \mathrm{O}_{40} /$ polymethylmethacrylate/polyvinyl alcohol sandwich nanofibrous membrane with enhanced photocatalytic activity," Colloids and Surfaces A: Physicochemical and Engineering Aspects, vol. 489, pp. 289-296, 2016.

[53] W. Li, T. Li, X. Ma, Y. Li, L. An, and Z. Zhang, "Electrospinning preparation of a $\mathrm{H}_{4} \mathrm{SiW}_{12} \mathrm{O}_{40}$ /polycaprolactam composite nanofibrous membrane and its greatly enhanced photocatalytic activity and mechanism," RSC Advances, vol. 6, pp. 1249112496, 2016.

[54] S. Li, W. Yang, and C. Li, "Preparation complex photocatalyst of modified TiO2/K2Ti6O13 by tungstosilicic acid and study its degradation of methyl orange," in 2010 International Conference on Challenges in Environmental Science and Computer Engineering, pp. 421-424, Wuhan, China, 2010. 

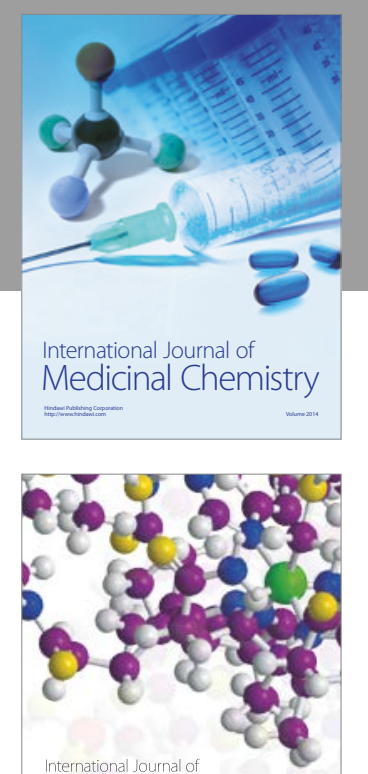

Carbohydrate Chemistry

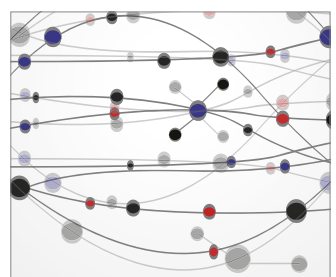

The Scientific World Journal
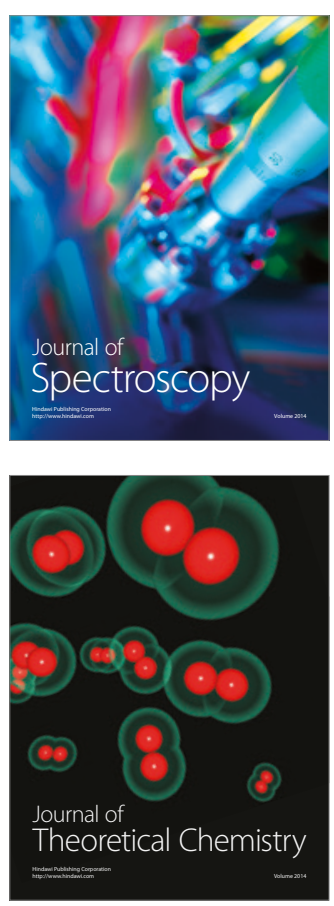
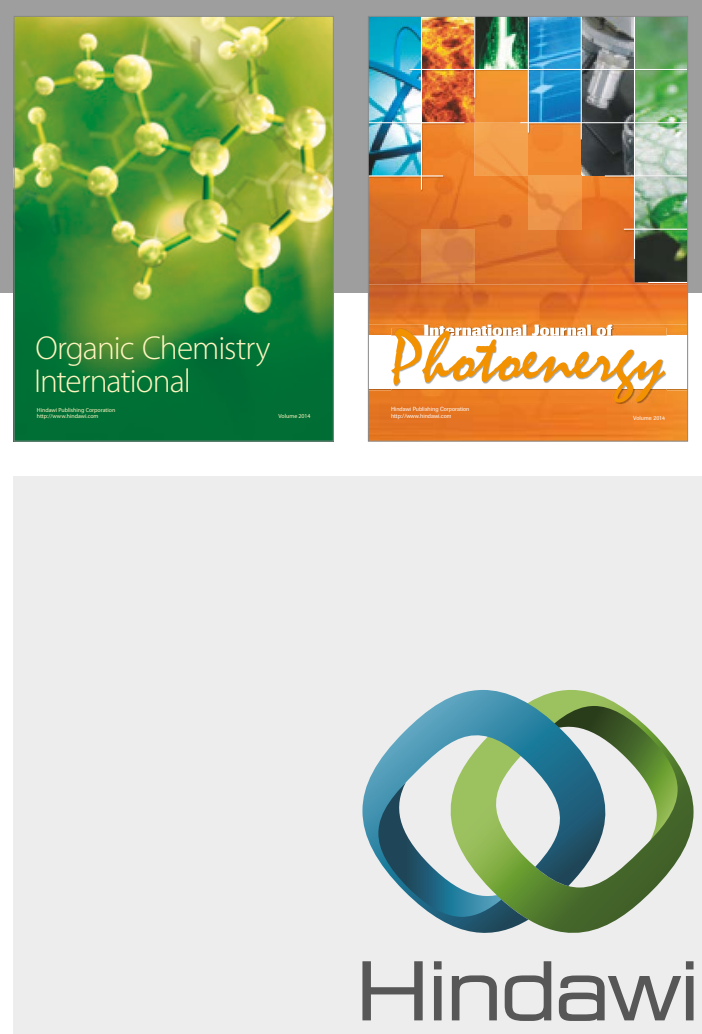

Submit your manuscripts at

https://www.hindawi.com

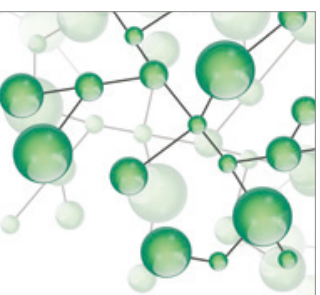

International Journal of

Inorganic Chemistry

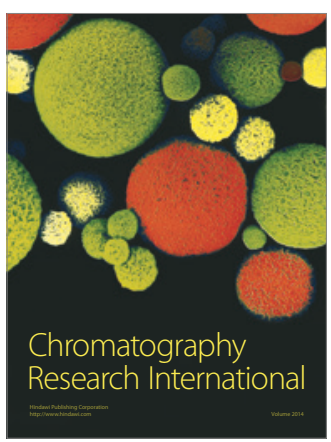

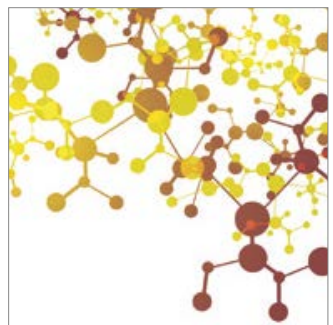

Applied Chemistry
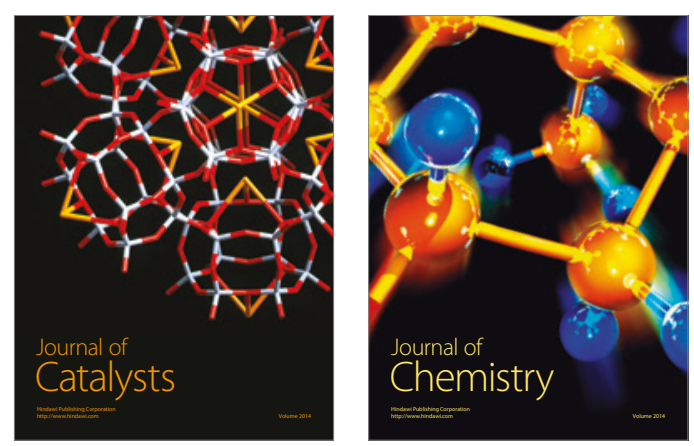
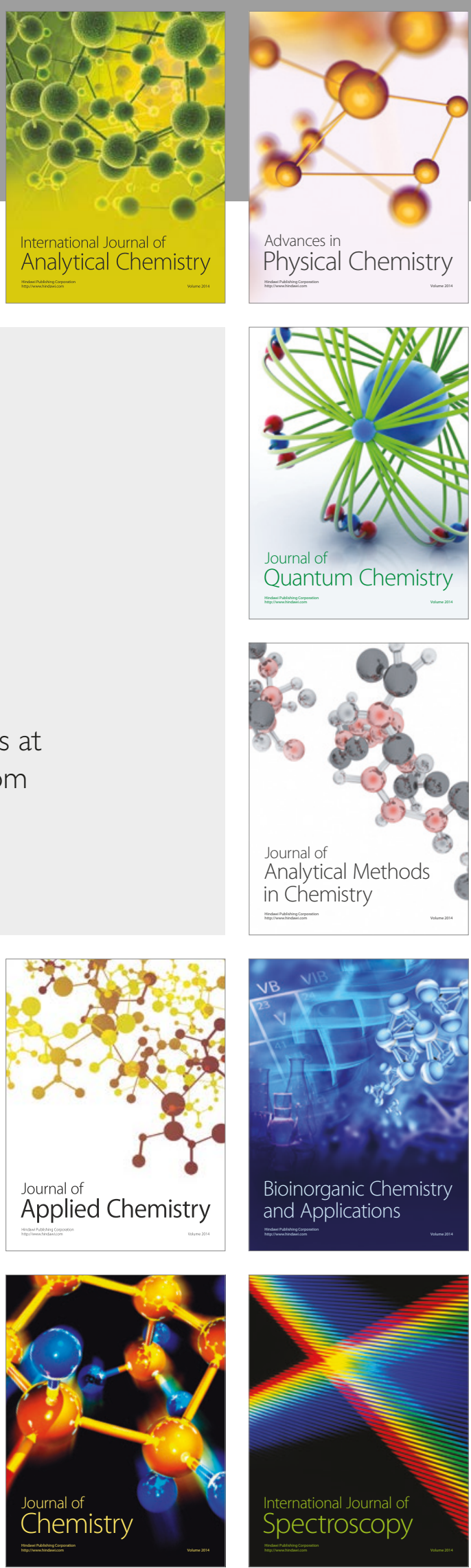